\title{
Arsenic Mobilization in an Oxidizing Alkaline Groundwater: Experimental Studies, Comparison and Optimization of Geochemical Modeling Parameters
}

Saeedreza Hafeznezami ${ }^{1}$, Jacquelyn R. Lam ${ }^{1}$, Yang Xiang ${ }^{2}$, Matthew D. Reynolds ${ }^{3}$, James A. Davis ${ }^{4}$, Tiffany Lin ${ }^{1}$, and Jennifer A. Jay ${ }^{1}$

1. Department of Civil and Environmental Engineering, UCLA 5732 Boelter Hall, Box 951593

Los Angeles, CA 90095-1593

2. Xiamen University

State Key Laboratory of Marine Environmental Science, 422 Siming S Rd, Siming, Xiamen, Fujian, China, 361006

3. Drumlin Environmental, LLC

97 India Street, Portland, ME 04101

4. Earth Sciences Division, Lawrence Berkeley National Laboratory, 1 Cyclotron Road, Berkeley, California 94720

Keywords: Arsenic, mobilization, groundwater contamination, remediation, geochemical modeling, surface complexation modeling, acidification, adsorption, natural attenuation, PHREEQC, FITEQL

\begin{abstract}
Arsenic (As) mobilization and contamination of groundwater affects millions of people worldwide. Progress in developing effective in-situ remediation schemes requires the incorporation of data from laboratory experiments and field samples into calibrated geochemical models.

In an oxidizing aquifer where leaching of high $\mathrm{pH}$ industrial waste from unlined surface impoundments led to mobilization of naturally occurring As up to $2 \mathrm{mg} \mathrm{L}^{-1}$, sequential extractions of solid phase As as well as, batch sediment microcosm experiments were conducted to understand As partitioning and solid-phase sorptive and buffering capacity. These data were combined with field data to create a series of geochemical models of the system with modeling programs PHREEQC and FITEQL. Different surface complexation modeling approaches, including component additivity (CA), generalized composite (GC), and a hybrid method were developed, compared and fitted to data from batch acidification experiments to simulate potential remediation scenarios. Several parameters strongly influence the concentration of dissolved As
\end{abstract}


including $\mathrm{pH}$, presence of competing ions (particularly phosphate) and the number of available sorption sites on the aquifer solids. Lowering the $\mathrm{pH}$ of groundwater to 7 was found to have a variable, but limited impact $(<63 \%)$ on decreasing the concentration of dissolved As. The models indicate that in addition to lowering $\mathrm{pH}$, decreasing the concentration of dissolved phosphate and/or increasing the number of available sorption sites could significantly decrease the As solubility to levels below $10 \mu \mathrm{g} \mathrm{L}^{-1}$. The hybrid and GC modeling results fit the experimental data well (NRMSE $<10 \%$ ) with reasonable effort and can be implemented in further studies for validation.

\section{Introduction}

\subsection{Background}

Arsenic (As), considered one of the most serious inorganic contaminants in drinking water can adversely impact human health and is recognized as a prominent environmental cause of cancer mortality worldwide (Smedley and Kinniburgh, 2002; Welch at al., 2000; Smith et al., 1992). Arsenic is a ubiquitous trace element in the environment and can be mobilized from solid phases through a combination of natural processes such as weathering reactions, biological activity and volcanic emissions as well as through a range of anthropogenic activities. Following the World Health Organization (WHO) guideline in 1993, the US Environmental Protection Agency (USEPA) reduced the maximum contaminant level (MCL) for As in drinking waters from 50 to 10 $\mu \mathrm{g} \mathrm{L}^{-1}$ in January 2001 (EPA, 2002; WHO, 2011).

While use of As containing compounds has decreased in recent decades and elevated levels of As in groundwater can generally be attributed to naturally occurring sources, anthropogenic activities such as agricultural and mining operations, industrial processes and associated waste disposals can still cause or facilitate favorable conditions for mobilization of As from geologic sources into groundwater. Arsenic is the second most common contaminant of concern in National Priorities List (NPL), occurring at 47\% of all Superfund sites in the US (EPA, 2002). High levels of As in the groundwaters of Bangladesh and West Bengal originate from natural sources with mobilization stimulated by anthropogenic inputs of natural organic matter (NOM) (Neumann et al., 2009; Harvey et al., 2006). 
Arsenic speciation and fate is controlled by the $\mathrm{pH}$ and redox potential (Eh) of the system, the presence of ligands such as NOM and competing ions, and the mineral present at the site. Arsenic in groundwater is primarily present as oxyanions of $\mathrm{As}(\mathrm{V})$ (arsenate), with pKa's of 2.2, 6.9 and 11.5 or As(III) (arsenite), with pKa's of 9.3 and 14.2 (Stollenwerk, 2003).

Arsenic mobilization from solid to aqueous phases can occur in both reducing and oxidizing environments. Many studies have focused on reducing conditions, under which both As and $\mathrm{Fe}$ may be reduced and mobilized by microbial activity, as is occurring in Bangladesh (Radloff et al., 2011; Ravenscroft et al., 2009; Van Geen et al., 2006; Oremland and Stolz, 2005; Zheng et al., 2004; Anawar et al., 2002 ), Vietnam (Mai et al., 2014; Larsen et al., 2008; Postma et al., 2007; Berg et al., 2001), Cambodia (Lawson et al. 2013; Omoregie et al., 2013; Quicksall et al., 2008; Rowland et al., 2007; Polya et al., 2005), West Bengal, India (Neidhardt et al. 2014; Lawson et al. 2013; Islam et al. 2004; McArthur et al., 2004 ). Fewer studies have addressed oxidizing conditions, in which As(V) may be mobilized by desorption at high pH (Nicolli et al., 2012; Currel et al. 2011; Scanlon et al., 2009; Bhattacharya et al., 2006; Smedley et al., 2005), and others have investigated As solubility under variable redox conditions (O'Day et al., 2004). Adsorption and coprecipitation on solid phases has been recognized as the principal factor in controlling As mobility in the environment (Wang et al., 2006). Sorption of As on Fe (III) (hydr)oxides is known as the most important process for limiting As solubility and has been investigated extensively. Due to their abundance in natural systems, high surface area and ability to adsorb As in large capacities, ferrihydrite (also referred to as amorphous hydrous ferric oxides or HFO) appears to be the most important solid phase responsible for removing As from the groundwater (Appelo and De Vet, 2003; Stollenwerk, 2003). The mechanism for specific adsorption has been described as ligand exchange reactions between ions in solution and surface functional groups leading to formation of both monodentate and bidentate inner-sphere complexes (Appelo and Postma, 2005; Sherman and Randall, 2003; Wilkie and Hering, 1996).

Efficiency of As adsorption onto Fe (III) oxides depends on a variety of factors such as the amounts and sorption capacity of minerals present, $\mathrm{pH}$, concentrations and oxidation state of As, and concentration of other dissolved species that compete with As for adsorption sites (Stollenwerk et al., 2007). Ferrihydrite which has an amphoteric surface has strong affinity for adsorption of arsenate in $\mathrm{pH}$ range of 4-8. Adsorption studies at varying $\mathrm{pH}$ levels on ferrihydrite 
have shown that arsenate adsorption is higher at low $\mathrm{pH}$ values due to the net positive charge of the surface attracting negatively charged $\mathrm{As}(\mathrm{V})$ species (Raven et al., 1998). At high $\mathrm{pH}$, arsenate adsorption becomes limited due to increased repulsion between the both negatively charged arsenate species and surface sites while arsenite can be retained in much larger amounts at such pH values due to its neutral charge (Masue et al., 2007; Dixit and Hering, 2003). Arsenic sorption can significantly be limited by presence of competing anions such as phosphate, silicates, bicarbonate and sulfate (Neupane et al., 2014; Kanematsu et al., 2012; Kanel et al., 2005; Dixit and Hering, 2003; Hongshao and Stanforth, 2001; Manning and Goldberg, 1996).

Efforts at applying geochemical modeling to simulate contamination and remediation scenarios in natural systems is challenging due to the complexity of interactions between groundwater and the solid matrix of the aquifer (Sharif et al., 2011). The majority of studies available on adsorption and surface complexation of trace contaminants have been conducted on pure mineral phases under controlled laboratory conditions. However, applicability of these findings to an environmental setting is limited due to the heterogeneous nature of aquifer media and the interactions among the various solid compositions.

Surface Complexation Models (SCM) for retention of trace elements such as As on natural heterogeneous solid phases can be categorized by two main approaches: (1) component additivity (CA) and (2) generalized composite (GC) (Davis et al., 1998). In the CA approach, it is assumed that the overall retention of solutes on a complex mineral assemblage can be described by combining the sorption results on the individual specific solid phases composing the sorbent mixture. This is possible by using databases developed from independent adsorption studies on the individual pure phases. The modeler needs to first adequately analyze the studied solid phase to characterize the composition of mineral mixture. Therefore in the CA approach the emphasis is usually on collecting mineralogical data for appropriate identification and quantification of solid phases responsible for sorption, without fitting the constants with experimental data.

In the GC approach, a generic solid surface is defined and assumed to represent the sorptive behavior of the entire mineral assemblage and site-specific surface characteristics are determined by conducting variety of experiments and fitting of data. Therefore, the GC approach focuses on investigating the site-specific holistic sorption characteristics of solid phases as a function of $\mathrm{pH}$, concentration of adsorbing ion, and influence of competing ions. The stoichiometry and surface 
complex formation constants are then determined by statistical methods and fitting the experimental data.

While the CA approach seems to be more sound in theory, applying it to heterogeneous solid surfaces has limitations. First, in many situations sufficiently characterizing the composition of the sediments may not be possible or practical. Second, due to heterogeneity of natural sediment surfaces, the different mineral phases could interact and behave very differently than expected based on the findings from studies of isolated pure phases under controlled conditions. Presence of secondary minerals, impure mixture of phases, interactions with NOM, organic coating and clay minerals makes application of SCMs to natural sediments more challenging. (Biswas et al., 2014; Jessen et al., 2012; Hiemstra et al., 2010). Because of the difficulty in describing the actual surface charge of complex solid mixtures, applying the $\mathrm{pH}$-dependent electrostatic correction terms required in the commonly used SCMs is not accurate for describing the adsorption on natural particles (Davis et al., 1998).

Also, the surface complexation mass-action reaction constants that are usually adopted from reference databases are developed from adsorption studies with constant background electrolyte concentrations in solution and will have limitations when applied to adsorption of solutes from the more complex natural groundwater systems. The intrinsic surface acidity constants are derived from titration experiments in simple electrolyte solutions and based on the assumption that only the functional groups control the acidity properties of the surface. However in natural systems, such as aquifers with calcareous lithology, presence of various ions in solution and dissolution of phases such as carbonates invalidate this assumption.

Sharif et al. (2011) signified the inherent uncertainty in using the CA approach and the need for properly determining the surface properties rather than relying on default site characteristics from literature. Jessen et al. (2012) showed that a site-specific developed GC model produced more satisfying results than using the default SCM models from literature.

On the other hand, successful application of the GC approach for a complex natural system with various competing ions and across a wide $\mathrm{pH}$ range requires an extensive series of adsorption studies in order to obtain an internally consistent and comprehensive set of reactions and constants. Therefore, developing a GC model for the purpose of practical application at a specific contaminated site can involve substantial laboratory studies. Another difficulty for implementing the GC method for natural sediments is the accurate determination of acidity constants for 
surface functional groups. Due to heterogeneity and possible dissolution of other phases (eg. carbonates), interpretation of acid-base titrations data for determining the surface charge of sediments become very complex. In most cases in order to achieve simplicity, the GC approach is applied without explicit representation of an electrostatic term (Sracek et al., 2004; Davis et al., 1998). Consequently the simplified model does not make electrostatic corrections to intrinsic complexation constants to account for changes in surface charge due to adsorption of ions.

Site specific $\mathrm{GC}$ has been successfully applied for uranium adsorption modeling purposes (Hyun et al., 2009; Bond et al., 2007; Davis et al., 2004), but applications for modeling As adsorption are rare. For example in a study on adsorption of As on oxidized sediments in Bangladesh (Stollenwerk et al., 2007) which was also shown promising for application in a different aquifer (Jessen et al., 2012).

As mentioned above, both the $\mathrm{CA}$ and $\mathrm{GC}$ approaches have certain difficulties for application in an impacted natural environment and in a timely efficient manner. Using laboratory and field data with the easily-accessible geochemical modeling tools PHREEQC and FITEQL, the current study aims at both comparing CA and GC approaches and also evaluating the effectiveness a hybrid $\mathrm{CA} / \mathrm{GC}$ modeling approach for practical application with the purpose of achieving engineering solutions. We test the hypothesis that a hybrid CA/GC approach to modeling can be an effective, efficient choice to guide As remediation efforts. Batch acidification experiments on natural sediment-groundwater microcosms are conducted in order to be the basis for development and comparison of the models as well as to evaluate the viability of this remedial approach.

\section{Materials and methods}

\subsection{Site Description}

The study site (Figure 1), located in New England, USA, is a former manufacturing facility at which approximately 5000 gallons per week of hydroxide-containing waste sludge were disposed in unlined surface impoundments during the second half of the 1970's. The high $\mathrm{pH}$ waste sludge is believed to have contained phosphate-based detergents and chelating agents as well as copper and other plating metals. Waste disposal in the impoundments ended in the early 1980 's and the impoundments were closed in early 1990's by removing the sludge and capping with low permeability cover material. 
The $\mathrm{As}(\mathrm{V})$ concentrations in the most affected areas of the site range from $140 \mu \mathrm{g} \mathrm{L} \mathrm{L}^{-1}$ to $800 \mu \mathrm{g}$ $\mathrm{L}^{-1}$. The source of arsenic in the groundwater is attributed mainly to the desorption and leaching from native solid phases into groundwater due to increased $\mathrm{pH}$ and phosphate concentrations. An association between an alkaline ground water $(\mathrm{pH}>8)$ and high arsenic has historically been found in several areas of the United States, including eastern New England where 20-30\% of private wells exceed the As drinking water standard (Ayotte et al. 2003, 2006; Welch at al., 2000; Robertson, 1989).

In previously collected ground water samples throughout the impacted areas, arsenic was present mainly as the oxidized form $\mathrm{As}(\mathrm{V})$. Oxidizing conditions at the site were evident by the Eh value ranges of samples and low Fe(II). The sampling results from 2011-2012 (unpublished data) showed dissolved oxygen (DO) ranging from 0.4 to $4.7 \mathrm{mg} \mathrm{L}^{-1}$ in impacted sites and $8.4 \mathrm{mg} \mathrm{L}^{-1}$ as background. The oxidation-reduction potential (ORP) measurements were between 60 to 130 $\mathrm{mV}$ in all samples indicating oxidizing conditions. X-ray diffraction (XRD) and scanning electron microscopy (SEM) analyses of the sediments showed that the mineralogical composition is dominated mainly by quartz and feldspars and all other phases were below the quantifiable limit of detection.

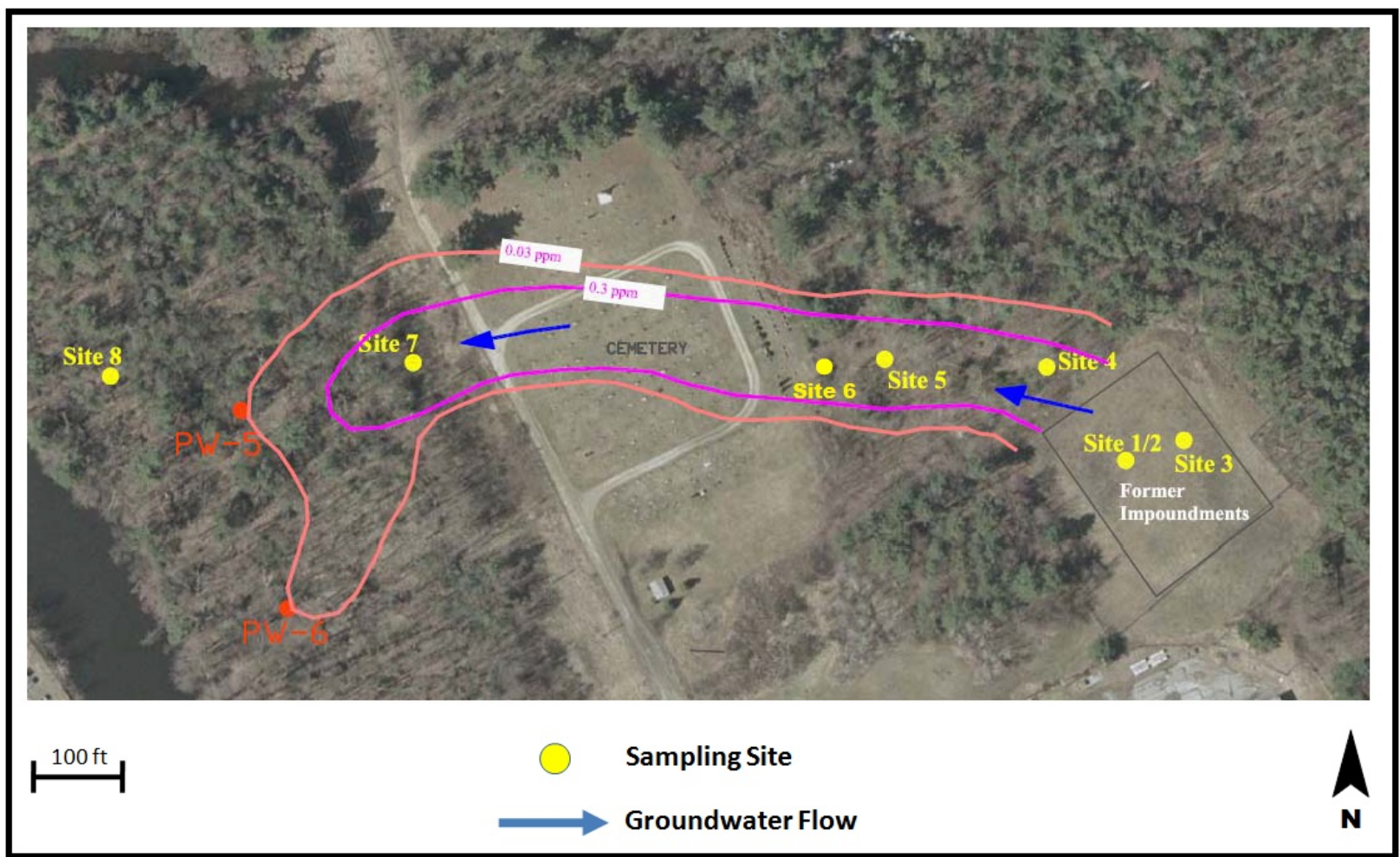


Figure 1. Map of the site showing the former impoundment location and extent of As plume (solid lines represent contours of dissolved As concentration).

\subsection{Sampling Locations}

Multiple co-located sediment and groundwater sampling locations were selected within and downstream of the former impoundment area where $\mathrm{As}(\mathrm{V})$ and $\mathrm{pH}$ values have been elevated. Site 2 is located beneath the former surface impoundments of waste materials and where the high $\mathrm{pH}$ conditions occurred. The sediment in this site consisted of a brown sandlens within the till

formation. Sediment at Site 4, which has the highest groundwater As(V) concentration, is gray till and based on screening tests with $\mathrm{HCl}$, calcite is present in the solid matrix. Soil from Site 6 was also grey till with evidence of calcite. Site 7 is located further downgradient within the known As(V) plume where the aquifer soil consists of sand and gravel. The $\mathrm{pH}$ has been elevated (i.e., $>8)$ at this location and $\operatorname{As}(V)$ concentrations are the second highest following Site 4. Site 8, characterized as a sand and gravel aquifer, is located downgradient, beyond the portion of the aquifer that has been impacted by the $\mathrm{As}(\mathrm{V})$ plume. The flow path indicates that over time, the plume could eventually reach site 8 .

\subsection{Sample Collection}

Both sediment and groundwater samples were collected from the previously described locations in 2013-2014 and shipped in coolers to UCLA. Soil borings were advanced with the drive and wash technique using 3-inch diameter steel casing and a two-foot long split spoon sampler ahead of the casing to collect undisturbed soil sample. Sediments collected from adjacent depth intervals were transferred to clean stainless steel containers, mixed thoroughly to form a composite sample representative of the depth intervals, and placed in glass screw-top jars. All samples were refrigerated $\left(4^{\circ} \mathrm{C}\right)$ in dark prior to and between experiments. Sample collection intervals and soil descriptions are provided in Table 1. 
Table 1. Sediment samples properties and descriptions

\begin{tabular}{ccccccc}
\hline Boring & $\begin{array}{c}\text { Sample } \\
\text { ID }\end{array}$ & $\begin{array}{c}\text { Depth } \\
\text { Interval } \\
\text { (ft) }\end{array}$ & $\begin{array}{c}\text { Soil } \\
\mathbf{p H}\end{array}$ & $\begin{array}{c}\text { Organic } \\
\text { Matter (\%) }\end{array}$ & $\begin{array}{c}\text { CEC } \\
\text { (meq/100g) }\end{array}$ & Description \\
\hline A & Site 1 & $22-29$ & 9.6 & 0.4 & 2.4 & $\begin{array}{c}\text { Gray Silty Sand } \\
\text { (Till) }\end{array}$ \\
A & Site 2 & $24-26$ & 9.3 & 0.2 & 1.1 & $\begin{array}{c}\text { Brown Fine- } \\
\text { Medium Sand } \\
\text { Gray-Brown } \\
\text { Silty Sand } \\
\text { (Till) }\end{array}$ \\
B & Site 3 & $25-31$ & 7.9 & 0.2 & 1.9 & $\begin{array}{c}\text { Gray Silty Sand } \\
\text { (Till) }\end{array}$ \\
C & Site 4 & $29-35$ & 8.3 & 0.2 & 1.2 & $\begin{array}{c}\text { Brown Fine } \\
\text { Sand }\end{array}$ \\
D & Site 5 & $25-28$ & 9.1 & 0.2 & 1.4 & $\begin{array}{c}\text { Gray Silty Sand } \\
\text { (Till) }\end{array}$ \\
D & Site 6 & $31-35$ & 8.3 & 0.2 & 1.8 & $\begin{array}{c}\text { Brown Medium } \\
\text { Sand }\end{array}$ \\
E & Site 7 & $47-55$ & 8.2 & 0.4 & 0.7 & $\begin{array}{c}\text { Brown Fine to } \\
\text { Coarse Sand }\end{array}$ \\
F & Site 8 & $51-58$ & 7.2 & 0.2 & 0.8 & \\
\hline
\end{tabular}

Borings A, C, D, E and F were advanced adjacent to monitoring wells screened at the same interval as the soil samples. Groundwater samples were collected from these wells using lowflow sampling techniques. The wells were purged using a peristaltic pump with dedicated LDPE tubing. Pumping rates were controlled to minimize drawdown to approximately 1 foot or less. Temperature, $\mathrm{pH}$ and specific conductance were monitored during purging until these parameters stabilized. Groundwater samples were collected in clean, unpreserved $250 \mathrm{ml}$ plastic bottles and refrigerated until use. Chemistry of the groundwater samples is presented in the supplementary materials (Table S-1). 


\subsection{Materials}

All solutions used in experiments were prepared with nanopure Milli-Q (18 M $\Omega$-cm) water. Before use, all polypropylene tubes and glass volumetric flasks were filled with $1.2 \mathrm{~N} \mathrm{HCl}$ and stored overnight prior to washing five times with Milli-Q water. All experiments were conducted in room temperature and in contact with the atmosphere.

\subsection{Analytical Methods}

The $\mathrm{pH}$ of the solutions was measured using an $\mathrm{AB} 15$ Plus $\mathrm{pH}$ meter, calibrated using commercial $\mathrm{pH} 4.0,7.0$, and 10.0 buffer solutions. Filtered solutions from adsorption isotherm experiments were analyzed for total As by Graphite Furnace Atomic Absorption Spectrometry (GFAAS). The instrument was calibrated daily and prior to use with 5 standard solutions made in the same matrix as the analyzed solution (linear dynamic range; $10-100 \mu \mathrm{g} \mathrm{L}^{-1}$ ). The analyses were conducted in triplicates with palladium-magnesium nitrate matrix modifiers and the relative standard deviations of measurements were below 5\%. The filtered solutions from sequential extractions and acidification experiments were analyzed for As and other elements by Inductively Coupled Plasma Mass Spectrometry (ICP-MS).

\subsection{Sequential Extractions/Total Digestion}

Oxalate and $\mathrm{PO}_{4}$ extractable steps from the procedure specified in Keon et al. (2001) and total digestion (EPA method 3050B) were were implemented sequentially for the extraction of solid phase As. $\mathrm{PO}_{4}$-extractable fraction represents the strongly-adsorbed As that is removed by anion exchange of $\mathrm{PO}_{4}{ }^{3-}$ for $\mathrm{AsO}_{4}{ }^{3-}$. Oxalate-extraction step targets As coprecipitated with amorphous Fe oxides and the removal process is cited as ligand promoted complexation and dissolution of $\mathrm{Fe}, \mathrm{Al}$ and $\mathrm{Mn}$ oxyhydroxides. Arsenic associated with crystalline Fe oxides, silicates and sulfides in addition to residual and other recalcitrant fractions are pooled in the total digestion (TD) step. Table 2 summarizes the extractants and procedures used. Sediment to extractant ratio of $5 \mathrm{~g}$ to $25 \mathrm{~mL}$ was used for all samples in duplicates. Separate extractions using hydroxylamine hydrochloride $\left(0.25 \mathrm{M} \mathrm{NH}_{2} \mathrm{OH}\right.$. $\mathrm{HC} 1$ in $0.25 \mathrm{M} \mathrm{HC} 1$, at $50^{\circ} \mathrm{C}$ for $\left.0.5 \mathrm{~h}\right)$ were also conducted on sediments as an alternative method of dissolution of poorly crystalline iron oxides. Samples were shaken in polypropylene centrifuge tubes for the specified time durations prior to being 
centrifuged for 25 minutes at $7800 \mathrm{rpm}$. Supernatants were filtered with $0.45 \mu \mathrm{m}$ filters and preserved with concentrated $\mathrm{HCl}(0.2 \% \mathrm{v} / \mathrm{v})$ prior to being analyzed by GFAAS.

Table 2. Sequential extraction method modified from Keon et al (2001)

\begin{tabular}{|c|c|c|}
\hline Step & Extractant & Target Phase \\
\hline $\mathrm{PO}_{4}$ & $\begin{array}{c}1 \mathrm{M} \mathrm{NaH}_{2} \mathrm{PO}_{4}, \mathrm{pH} 5,16 \& \\
24 \mathrm{hr}, 25^{\circ} \mathrm{C} \\
1 \text { repetition each time } \\
\text { duration, } 1 \text { water wash }\end{array}$ & Strongly-adsorbed As \\
\hline Oxalate & $\begin{array}{c}0.2 \mathrm{M} \text { ammonium } \\
\text { oxalate/oxalic acid, } \mathrm{pH} 3, \\
2 \mathrm{hr}, 25^{\circ} \mathrm{C} \text { in dark } \\
1 \text { repetition, } 1 \text { water wash }\end{array}$ & $\begin{array}{l}\text { As precipitated with amorphous } \\
\text { Fe oxyhydroxides }\end{array}$ \\
\hline Hot $\mathrm{HNO}_{3}$ & $\begin{array}{l}15 \mathrm{~N} \mathrm{HNO}_{3}+30 \% \mathrm{H}_{2} \mathrm{O}_{2} \\
\text { EPA method } 3050 \mathrm{~B}\end{array}$ & $\begin{array}{l}\text { As oxides, As coprecipitated with } \\
\text { silicates, pyrites, and amorphous } \\
\mathrm{As}_{2} \mathrm{~S}_{3} \text {, orpiment \& other } \\
\text { remaining recalcitrant As minerals }\end{array}$ \\
\hline
\end{tabular}

\subsection{Batch Adsorption Experiments}

For adsorption isotherm experiments, sediments were mixed with $0.1 \mathrm{M} \mathrm{NaCl}$ background electrolyte solutions in polypropylene centrifuge tubes (1:10 sediment/solution ratio) and adjusted to $\mathrm{pH} 7$ before addition of $\mathrm{As}(\mathrm{V})\left(\mathrm{Na}_{2} \mathrm{HAsO}_{4} .7 \mathrm{H}_{2} \mathrm{O}\right.$, Sigma-Aldrich, ACS reagent grade) to final concentrations ranging from 50 to $10,000 \mu \mathrm{g} / \mathrm{L}$. Sample tubes were stored at room temperature and allowed to equilibrate on a rotary mixer at 8 RPM continuously for 7 days. Solutions were centrifuged, filtered $(0.45 \mu \mathrm{m})$ and preserved with concentrated $\mathrm{HCl}(0.2 \% \mathrm{v} / \mathrm{v})$ prior to total As analysis by GFAAS. The concentration of adsorbed As was calculated by conducting mass balance between the initial spiked concentration and the final concentration in filtered supernatant.

The Langmuir isotherm is a very commonly used empirical adsorption model with the physical basis that solids have a limited sorption capacity which could be reached at high concentrations of solutes. In comparison to other common models such as Freundlich, application of the Langmuir isotherm in soils and sediments studies has the advantage of providing an adjustable 
parameter that accounts for the maximum sorption capacity of sorbents. The Langmuir equation is as expressed as:

$$
S=S_{t} \frac{K C}{1+K C}
$$

where $\mathrm{S}$ is the adsorbed concentration $\left(\mathrm{mg} \mathrm{kg}^{-1}\right), \mathrm{S}_{\mathrm{t}}$ is the maximum sorption capacity $\left(\mathrm{mg} \mathrm{kg}^{-1}\right)$, $\mathrm{K}$ is a parameter representing the binding affinity $\left(\mathrm{L} \mathrm{mg}{ }^{-1}\right)$, and $\mathrm{C}$ is the equilibrium concentration in the solution phase $\left(\mathrm{mg} \mathrm{L}^{-1}\right)$.

\subsection{Batch Acidification Experiments}

Batch acidification experiments were conducted to evaluate whether lowering the $\mathrm{pH}$ to practically achievable levels $(\mathrm{pH} 7)$ in the field would re-establish a sorptive environment for $\mathrm{As}(\mathrm{V})$ and decrease the dissolved concentrations significantly. Oxic groundwater samples from Sites 4, 6, 7 and 8 were shaken and mixed with the corresponding site's sediment in triplicates using $1 \mathrm{~g}: 10 \mathrm{~mL}$ solid to solution ratio. Sets of the samples from each site were acidified to lower $\mathrm{pH}$ target levels and one set served as the control with no acidification. Samples were capped and continuously mixed with orbital shaker during the experiment. $\mathrm{pH}$ values were recorded before and after the initial mixture and also as the acidification progressed by adding increments of $1 \mathrm{~N}$ HCl. pH values were measured and adjusted daily to keep at the target values.

Following the stabilization of the $\mathrm{pH}$ levels (12 days), the triplicate suspensions were centrifuged, supernatant filtered $(0.45 \mu \mathrm{m})$ and preserved by adding concentrated $\mathrm{HCl}$ to $0.2 \%$ $\mathrm{v} / \mathrm{v}$.

\subsection{Acid Titrations}

Understanding the pH-buffering capacity of the sediment and groundwater is critical for assessing the potential effectiveness and practicality of in-situ remediation by acidification. In order to further understand the buffering behavior of aquifer systems, acid titrations were conducted for Sites 4 and 7 in batch setting. For each site, three sets of conditions were studied in duplicate: (1) suspensions of sediment and $0.1 \mathrm{M} \mathrm{NaCl}$ electrolyte solution; (2) suspensions of sediment and corresponding groundwater; (3) groundwater alone. Suspensions were mixed at 
solid/solution ratio of 1:10. The titrations were performed with incremental addition of $0.1 \mathrm{~N}$ $\mathrm{HCl}$ under continuous $\mathrm{N}_{2}$ atmosphere and stirring.

\subsection{BET Surface Area}

Surface areas of samples were measured by $\mathrm{N}_{2}$ and $\mathrm{Kr}$ adsorption isotherm using Micromeritics ASAP 2020 instrument by Brunauer-Emmett-Teller (BET) method.

\subsection{Geochemical Modeling}

The geochemical modeling computer program, PHREEQC Interactive Version 3 (Parkhurst and Appelo, 2013) was used for calculating chemical equilibrium speciation, mineral saturation indices, and to simulate the adsorption of As and other solutes using surface complexation modeling (SCM). The Minteq.v4 (Allison et al., 1990) database containing the thermodynamic data for major aqueous species and mineral phases was selected and used with certain modifications and additions as necessary.

Four different types of models were constructed for predicting and fitting the acidification experimental data in each sampling site. The models are described below and Table 3 presents the comparison among the model parameters and assumptions.

Table 3. Surface Complexation Model parameters and assumptions 


\begin{tabular}{|c|c|c|c|c|}
\hline Model Name & Total Surface Site Estimation & $\begin{array}{l}\text { Surface Site } \\
\text { Type }\end{array}$ & $\begin{array}{l}\text { Electrostatic } \\
\text { Model }\end{array}$ & Surface Reaction Constants \\
\hline CA-Hydroxylamine & $\begin{array}{l}\text { Chemical Extraction of } \\
\text { Amorphous Fe Oxides } \\
\text { (Hydroxylamine Hydrochloride) }\end{array}$ & $\begin{array}{l}\text { HFO Weak } \\
\text { Site }\end{array}$ & $\begin{array}{l}\text { Diffuse Double } \\
\text { Layer (DDL) }\end{array}$ & HFO Database (Non-fitted) \\
\hline CA-Oxalate & $\begin{array}{l}\text { Chemical Extraction of } \\
\text { Amorphous Fe Oxides } \\
\text { (Ammonium Oxalate/Oxalic Acid) }\end{array}$ & $\begin{array}{l}\text { HFO Weak } \\
\text { Site }\end{array}$ & $\begin{array}{l}\text { Diffuse Double } \\
\text { Layer (DDL) }\end{array}$ & HFO Database (Non-fitted) \\
\hline GC-BET & BET Surface Area Measurement & Generic Site & $\begin{array}{l}\text { Non- } \\
\text { Electrostatic }\end{array}$ & Experimental Data (Fitted) \\
\hline Hybrid-Isotherm & Adsorption Isotherm (Langmuir) & $\begin{array}{l}\text { HFO Weak } \\
\text { Site }\end{array}$ & $\begin{array}{l}\text { Diffuse Double } \\
\text { Layer (DDL) }\end{array}$ & $\begin{array}{l}\text { Experimental Data (Fitted) and } \\
\text { HFO Database (Non-fitted) }\end{array}$ \\
\hline
\end{tabular}

\subsubsection{Component Additivity-Electrostatic Models}

Two of the models followed the CA approach and used electrostatic correction terms for describing the electrical double layer (referred to hereafter as CA-Oxalate and CAHydroxylamine model). For the electrostatic models, hydrous ferric oxide (HFO) was assumed to be the main reactive surface site assigned for adsorption of As and other solutes, in accordance with the internally consistent database of Diffuse Double Layer (DDL) model (Dzombak and Morel, 1990). The selected SCM accounts for ligand exchange reactions between solutes and surface hydroxyl groups and also the $\mathrm{pH}$ dependent surface charge of sorbent sites.

The method used for estimating the surface site concentration is the major distinction between the electrostatic models. Total sorption sites were calculated in these two models, using the Fe concentrations released from chemical extractions of amorphous iron minerals by oxalate and hydroxylamine hydrochloride extractants. The calculations for total binding sites in CA models were conducted considering the assumed density of $0.2 \mathrm{~mol}$ of weak adsorption sites per mol of Fe. 
The published surface reaction stoichiometries and complexation constants for HFO were used in these models without fitting to predict the data. The thermodynamic reactions and constants for surface complexation of major competing ions with HFO were incorporated in the model from reference sources (Dzombak and Morel ,1990; Allison, 1990; Swedlund and Webster, 1999; Appelo et al., 2002). Table 4 lists the intrinsic reaction constants for adsorption of As and other ions on HFO included in the PHREEQC input.

Table 4. Surface complexation stoichiometry and reaction constants used in the diffuse double layer model for HFO

\begin{tabular}{|c|c|c|}
\hline Surface Complexation Reaction & $\log K$ & Reference \\
\hline \multicolumn{3}{|l|}{ Surface Acidity } \\
\hline Hfo_sOH $+\mathrm{H}+=$ Hfo_sOH2+ & 7.29 & \multirow{4}{*}{ Dzombak and Morel (1990) } \\
\hline $\mathrm{Hfo} \_\mathrm{wOH}+\mathrm{H}+=\mathrm{Hfo} \_\mathrm{wOH} 2+$ & 7.29 & \\
\hline Hfo_sOH $=$ Hfo_sO- $+\mathrm{H}+$ & -8.93 & \\
\hline Hfo_wOH $=$ Hfo_wO- $+\mathrm{H}+$ & -8.93 & \\
\hline \multicolumn{3}{|l|}{ Arsenate } \\
\hline Hfo_sOH + H3AsO4 = Hfo_sH2AsO4 + H2O & 8.61 & \multirow{8}{*}{ Dzombak and Morel (1990) } \\
\hline $\mathrm{Hfo} \_\mathrm{wOH}+\mathrm{H} 3 \mathrm{AsO} 4=\mathrm{Hfo} \_\mathrm{wH} 2 \mathrm{AsO} 4+\mathrm{H} 2 \mathrm{O}$ & 8.61 & \\
\hline $\mathrm{Hfo} \_\mathrm{sOH}+\mathrm{H} 3 \mathrm{AsO} 4=\mathrm{Hfo} \_\mathrm{sHAsO} 4-+\mathrm{H} 2 \mathrm{O}+\mathrm{H}+$ & 2.81 & \\
\hline Hfo_wOH + H3AsO4 = Hfo_wHAsO4- + $\mathrm{H} 2 \mathrm{O}+\mathrm{H}+$ & 2.81 & \\
\hline $\mathrm{Hfo} \_\mathrm{sOH}+\mathrm{H} 3 \mathrm{AsO} 4=\mathrm{Hfo} \_\mathrm{sHAsO} 4-2+\mathrm{H} 2 \mathrm{O}+2 \mathrm{H}+$ & -4.7 & \\
\hline $\mathrm{Hfo} \_\mathrm{wOH}+\mathrm{H} 3 \mathrm{AsO} 4=\mathrm{Hfo} \_\mathrm{wHAsO} 4-2+\mathrm{H} 2 \mathrm{O}+2 \mathrm{H}+$ & -4.7 & \\
\hline Hfo_sOH + H3AsO4 = Hfo_sOHAsO4-3 + 3H+ & -10.12 & \\
\hline Hfo_wOH + H3AsO4 = Hfo_wOHAsO4-3 + 3H+ & -10.12 & \\
\hline \multicolumn{3}{|l|}{ Arsenite } \\
\hline Hfo_sOH $+\mathrm{H} 3 \mathrm{AsO} 3=\mathrm{Hfo} \_\mathrm{sH} 2 \mathrm{AsO} 3+\mathrm{H} 2 \mathrm{O}$ & 5.41 & \multirow{2}{*}{ Dzombak and Morel (1990) } \\
\hline Hfo_wOH + H3AsO3 = Hfo_wH2AsO3 + H2O & 5.41 & \\
\hline \multicolumn{3}{|l|}{ Phosphate } \\
\hline Hfo_sOH + PO4-3 + 3H+ = Hfo_sH2PO4 + H2O & 31.29 & \multirow{6}{*}{ Dzombak and Morel (1990) } \\
\hline $\mathrm{Hfo} \_\mathrm{wOH}+\mathrm{PO} 4-3+3 \mathrm{H}+=\mathrm{Hfo} \_\mathrm{wH} 2 \mathrm{PO} 4+\mathrm{H} 2 \mathrm{O}$ & 31.29 & \\
\hline Hfo_sOH + PO4-3 + 2H+ = Hfo_sHPO4- + H2O & 25.39 & \\
\hline $\mathrm{Hfo} \_\mathrm{wOH}+\mathrm{PO} 4-3+2 \mathrm{H}+=\mathrm{Hfo} \_w \mathrm{HPO} 4-+\mathrm{H} 2 \mathrm{O}$ & 25.39 & \\
\hline Hfo_sOH + PO4-3 + H+ = Hfo_sPO4-2 + H2O & 17.72 & \\
\hline Hfo_wOH + PO4-3 + H+ = Hfo_wPO4-2 + H2O & 17.72 & \\
\hline \multicolumn{3}{|l|}{ Carbonate } \\
\hline Hfo_wOH + CO3-2 + H+ = Hfo_wCO3- + H2O & 12.56 & \multirow{2}{*}{ Appelo et al. (2002) } \\
\hline $\mathrm{Hfo} \_\mathrm{wOH}+\mathrm{CO} 3-2+2 \mathrm{H}+=\mathrm{Hfo} \_w \mathrm{HCO} 3+\mathrm{H} 2 \mathrm{O}$ & 20.62 & \\
\hline \multicolumn{3}{|l|}{ Silicic Acid } \\
\hline Hfo_sOH + H4SiO4 = Hfo_sH3SiO4 + H2O & 4.28 & Swedlund and Webster (1999) \\
\hline
\end{tabular}




\begin{tabular}{|c|c|c|}
\hline $\mathrm{Hfo} \_w O H+\mathrm{H} 4 \mathrm{SiO} 4=\mathrm{Hfo} \_w \mathrm{H} 3 \mathrm{SiO} 4+\mathrm{H} 2 \mathrm{O}$ & 4.28 & \\
\hline Hfo_sOH $+\mathrm{H} 4 \mathrm{SiO} 4=\mathrm{Hfo} \_\mathrm{sH} 2 \mathrm{SiO} 4-+\mathrm{H} 2 \mathrm{O}+\mathrm{H}+$ & -3.22 & \\
\hline $\mathrm{Hfo} \_\mathrm{wOH}+\mathrm{H} 4 \mathrm{SiO} 4=\mathrm{Hfo} \_\mathrm{wH} 2 \mathrm{SiO} 4-+\mathrm{H} 2 \mathrm{O}+\mathrm{H}+$ & -3.22 & \\
\hline $\mathrm{Hfo} \_\mathrm{sOH}+\mathrm{H} 4 \mathrm{SiO} 4=\mathrm{Hfo} \_\mathrm{sHSiO} 4-2+\mathrm{H} 2 \mathrm{O}+2 \mathrm{H}+$ & -11.69 & \\
\hline Hfo_wOH + H4SiO4 = Hfo_wHSiO4-2 + $\mathrm{H} 2 \mathrm{O}+2 \mathrm{H}+$ & -11.69 & \\
\hline Calcium & & \\
\hline Hfo_sOH $+\mathrm{Ca}+2=\mathrm{Hfo} \_\mathrm{sOHCa}+2$ & 4.97 & \multirow{2}{*}{ Dzombak and Morel (1990) } \\
\hline Hfo_wOH $+\mathrm{Ca}+2=\mathrm{Hfo} \_w O C a++\mathrm{H}+$ & -5.85 & \\
\hline \multicolumn{3}{|l|}{ Ferrous Iron } \\
\hline $\mathrm{Fe}+2+\mathrm{Hfo} \_w O H=\mathrm{Hfo} \_w O F e++\mathrm{H}+$ & -2.98 & \\
\hline $\mathrm{Fe}+2+\mathrm{Hfo} \_\mathrm{wOH}+\mathrm{H} 2 \mathrm{O}=\mathrm{Hfo} \_w O F e O H+2 \mathrm{H}+$ & -11.55 & Appelo et al. (2002) \\
\hline $\mathrm{Fe}+2+\mathrm{Hfo} \_\mathrm{sOH}=\mathrm{Hfo} \_\mathrm{sOFe}++\mathrm{H}+$ & -0.95 & \\
\hline
\end{tabular}

\subsubsection{Generalized Composite-NEM Model}

This model (referred to hereafter as the GC-BET model ) followed the GC approach strictly, without including the electrostatic factor (non-electrostatic model, NEM). The BET surface area measurements were used to calculate surface site concentrations using the $3.84 \mu \mathrm{mol} / \mathrm{m}^{2}$ site density in the GC model without including the electrostatic energy terms (Davis et al., 1998). This estimation method normalizes the contributions of all active sorbent phases to a defined average generic site. In this model, the complexity introduced by the DDL theory is not considered and the $\mathrm{pH}$ dependence of adsorption is incorporated into the surface reaction constants fitted to the experimental data.

\subsubsection{Hybrid Model}

The CA/GC hybrid model (referred to hereafter as the Hybrid-Isotherm model) is similar to the CA models in terms of representation of electrostatic energy terms, however it uses a more generalized method for estimating the sorbent site density and the surface reaction constants for $\mathrm{As}(\mathrm{V})$ and phosphate are fitted to experimental data.

The Langmuir-derived $\mathrm{S}_{\mathrm{t}}$ parameter (mg As/ $\mathrm{kg}$ sediment) values determined from the adsorption isotherm experiments were used to calculate the amount of surface sites in the hybrid model. In the Hybrid-Isotherm based method, a single surface site type based on the HFO characteristics and consistent with the DDL model was employed to simulate the data by allowing the modification of the reaction constants. The hybrid model uses HFO with the surface acidity 
constants and electrostatic correction terms of DDL model, as a surrogate site for adsorption of solutes.

\subsubsection{Model Application}

Models were run in PHREEQC to simulate the concentration of major parameters as a function of $\mathrm{pH}$ for comparison with the acidification experimental data. The groundwater monitoring data and the acidification experiment control samples from current study were used to compile the solution input variables in the models. The values derived for surface site densities were normalized considering the solid to solution ratio used in the acidification experiments.

Depending on goodness of fit with the experimental data, the Hybrid-Isotherm and GC-BET models were iteratively run to achieve the best fits by optimizing the complexation reaction constants for surface species at each site. Hybrid-Isotherm model simulations were initially run using the surface complexation reaction constant values reported for HFO in literature as default values (Table 4). FITEQL (Herbelin and Westall, 1999) was employed to estimate the new adsorption equilibrium constants (log $\mathrm{K}$ values) fitting the experimental data in the GC-BET models by using nonlinear least square optimization method. The surface complexation constants in the GC-BET model were fitted first individually and then in combination for the reactions associated with the dominant surface species that would improve the fits. Generic surface sites (site_z) without electrostatic considerations were defined and used instead of the default HFO database in the PHREEQC input to react with As(V).

The increase observed in concentrations of dissolved $\mathrm{Ca}$ from acidification experiments were used to estimate the starting amount of calcite present as the mineral phase in each site. The models were also run and compared to the acid titration experiments in order to revise the concentrations and phases responsible for the observed buffering to be included in the inputs.

The modeling was carried out first to simulate the acidification experiments as explained above and then used with certain alterations to assess several possible remediation approaches. Figure 2 illustrates the schematic conceptual framework for constructing the models. 


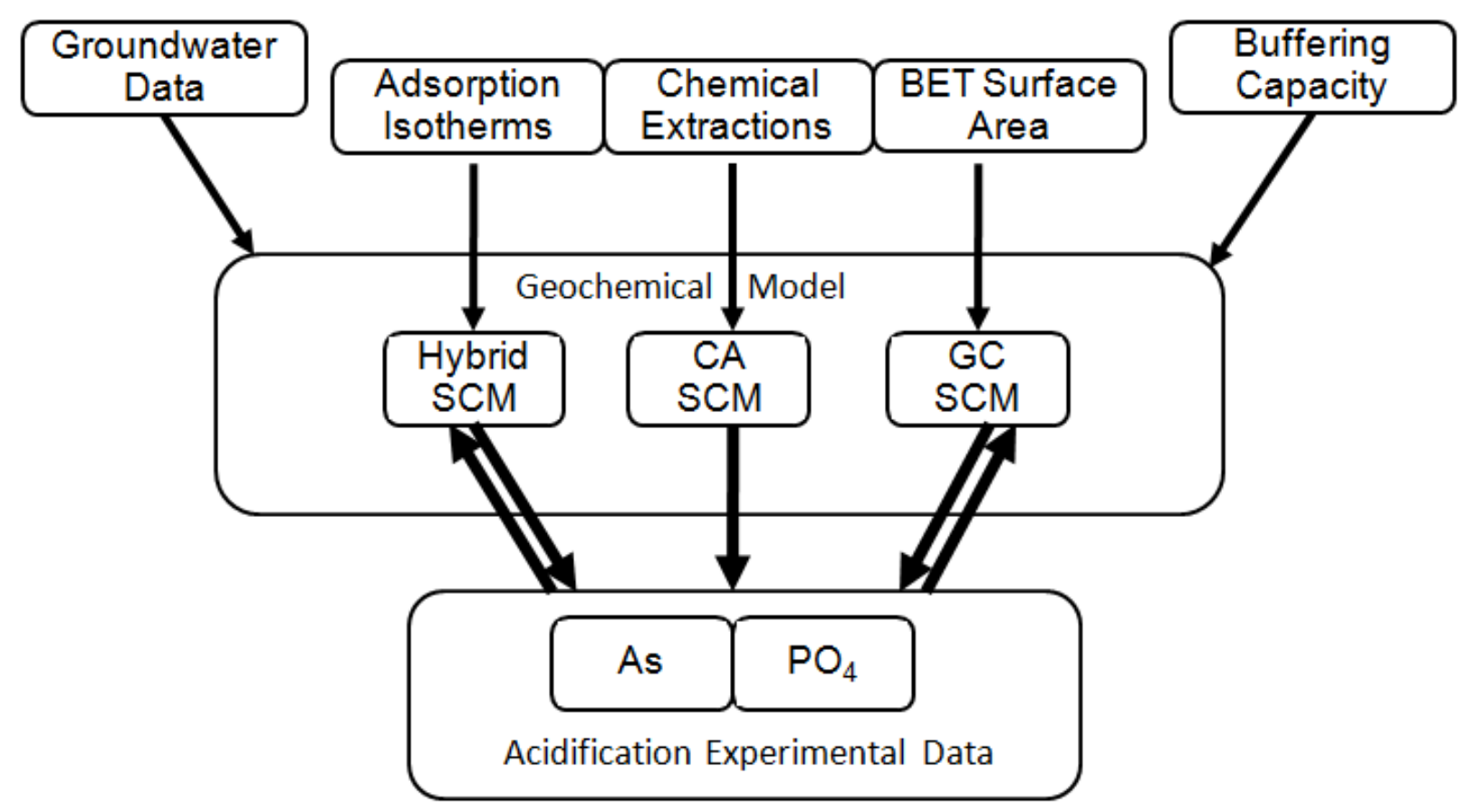

Figure 2. Schematic framework of geochemical modeling procedure implemented in this study.

\section{Results}

\subsection{Historical Data.}

Figure 3 shows the summary of historical $\mathrm{pH}$ trends and corresponding $\mathrm{As}(\mathrm{V})$ concentrations from selected groundwater monitoring wells within the area impacted by the contamination. A general relationship between the trends of elevated $\mathrm{As}(\mathrm{V})$ concentrations and occurrence of high $\mathrm{pH}$ values exists, suggesting that $\mathrm{pH}$ was a major factor controlling the mobility of $\mathrm{As}(\mathrm{V})$ in the groundwater. 

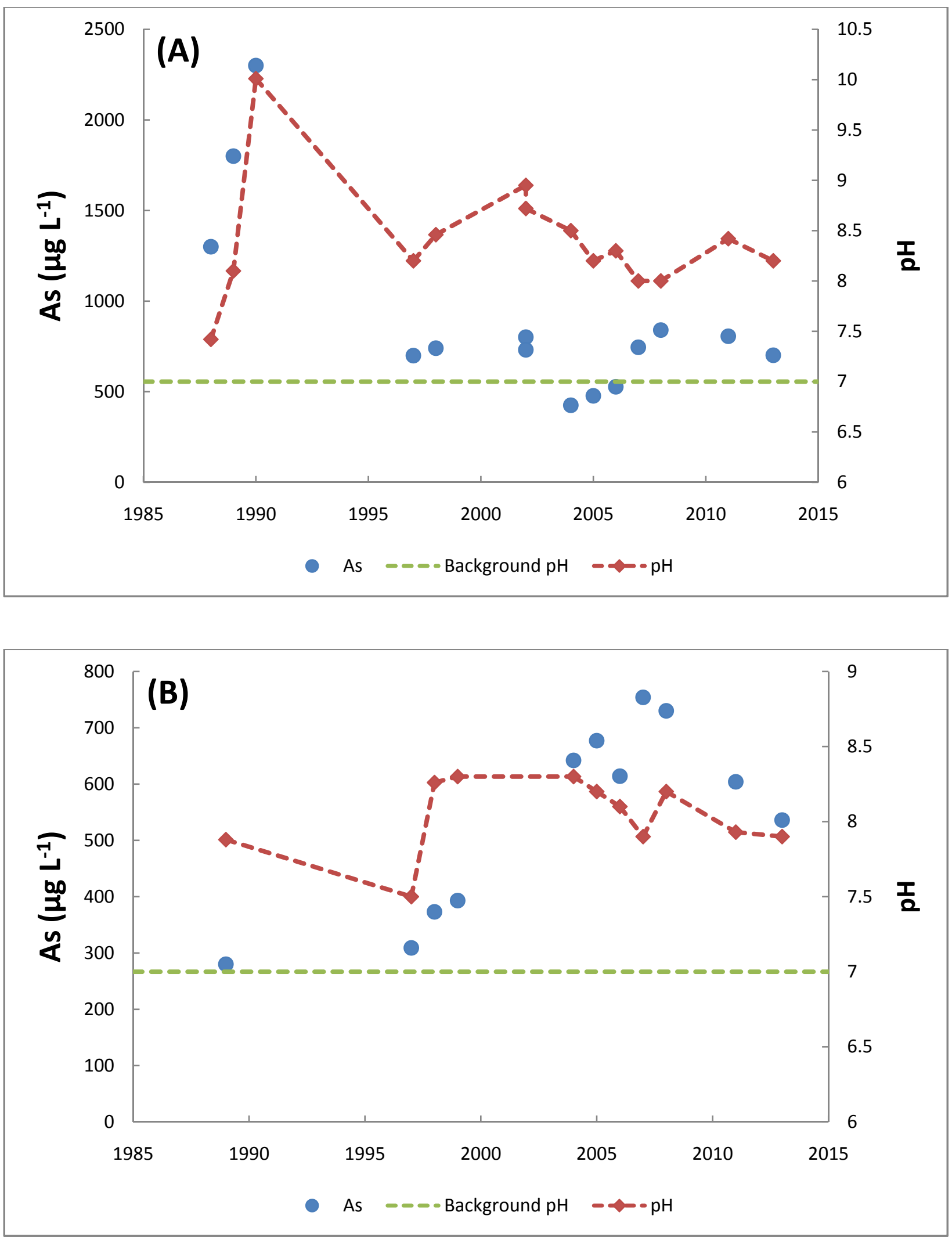
Figure 3. As concentrations and $\mathrm{pH}$ values at monitoring wells near (A) Site 4 and (B) Site 7 sampling locations, downgradient of waste impoundments.

\subsection{Total As and Sequential Extractions}

Total As in sediments ranged from 4.1 to $11.3 \mathrm{mg} \mathrm{kg}^{-1}$, comparable to the global average of 5-7.5 $\mathrm{mg} \mathrm{kg}^{-1}$ (Alloway 2013). Locations composed of brown sand, sites 2, 7 and 8 had lower total solid phase As concentrations (5.5, 4.1, and $4.7 \mathrm{mg} \mathrm{kg}^{-1}$ ) while gray till sites 4 and 6 had higher values of 11.3 and $10.3 \mathrm{mg} \mathrm{kg}^{-1}$, respectively. In all sites, the recalcitrant fraction makes up the majority of the solid phase As similar to the findings of Jay et al. (2005). This fraction includes As associated with crystalline oxide phases, silicates, and sulfides which are considered potential long-term sinks for As in sediments.

In sites 4 and 6, the percentages of As associated with either of the labile phases, strongly adsorbed or amorphous Fe, were lower than for the other three sites, indicating a larger fraction of As was present in recalcitrant forms (Figure 4 and Table 5).

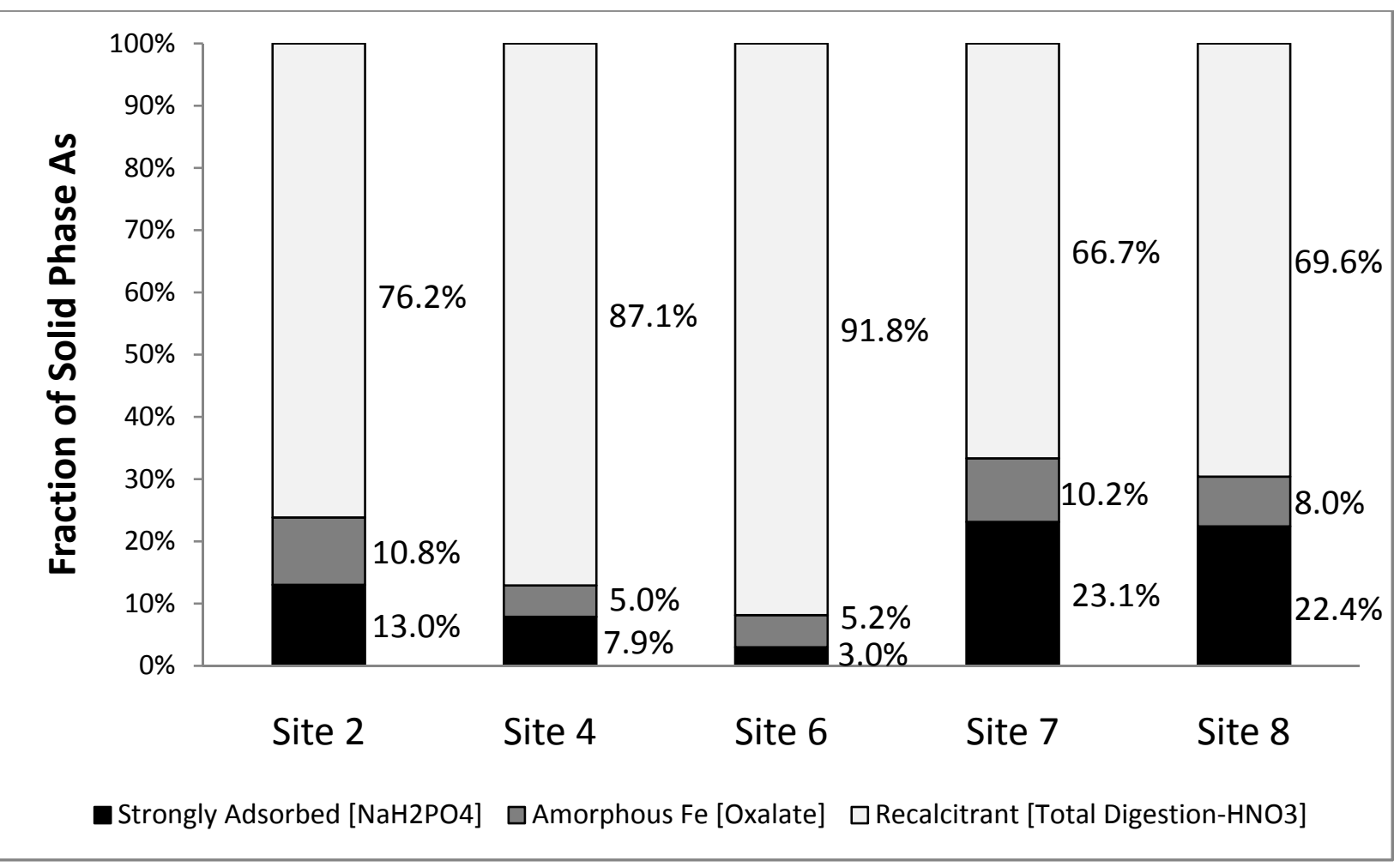


Figure 4. Distribution of solid phase As concentrations derived from sequential extraction of sediment samples.

Table 5. Distribution of solid phase As concentrations from sequential extractions

\begin{tabular}{ccccc}
\hline & \multicolumn{3}{c}{ As Fractions [Extractants] $\left(\mathrm{mg} \mathrm{kg}^{-1}\right)$} & \\
\cline { 2 - 4 } Sample & $\begin{array}{c}\text { Strongly } \\
\text { Adsorbed } \\
{\left[\mathrm{NaH}_{2} \mathbf{P O}_{4}\right]}\end{array}$ & $\begin{array}{c}\text { Amorphous } \\
\text { Fe [Oxalate] }\end{array}$ & $\begin{array}{c}\text { Recalcitrant [Total } \\
\left.\text { Digestion-HNO }{ }_{3}\right]\end{array}$ & Total As \\
\hline Site 2 & 0.71 & 0.59 & 4.2 & 5.5 \\
Site 4 & 0.89 & 0.57 & 9.9 & 11.3 \\
Site 6 & 0.31 & 0.53 & 9.5 & 10.3 \\
Site 7 & 0.94 & 0.42 & 2.7 & 4.1 \\
Site 8 & 1.1 & 0.38 & 3.3 & 4.7 \\
\hline
\end{tabular}

The results also indicate that the downgradient sites ( 7 and 8 ) have lower total As, but a higher percentage of exchangeable As. While sites 2, 7, and 8 are similar with higher fractions in both labile phases, site 2 which is upgradient, has lower As (both in absolute terms and percentage) in the adsorbed phase. This is what would be expected after significant mobilization of As occurring in upgradient locations.

\subsection{Adsorption Isotherms}

Adsorption isotherms are useful empirical tools for studying mobility and fate of contaminants in natural environments. Researchers have used the Langmuir isotherm in both $\mathrm{pH}$ dependent adsorption and transport models for As (Jeppu et al., 2012; Radu et al., 2008). The maximum adsorption capacity derived from the Langmuir model was one of the methods used in this study to estimate the concentration of sorption sites in the CA/GC approach.

The Langmuir isotherm parameters of $\mathrm{K}$ (binding strength coefficient, $\mathrm{L} \mathrm{mg}^{-1}$ ) and $\mathrm{S}_{\mathrm{t}}$ (maximum sorption capacity, $\mathrm{mg} \mathrm{kg}^{-1}$ ) were calculated by using the non-linear regression fit spreadsheet developed by Bolster, 2007. The use of non-linear regression was selected in order to avoid the statistical limitations caused by using the linearized forms of the Langmuir equation.

Results showed that the un-impacted Site 8, which is located outside of the known boundaries of the plume, has the highest $S_{t}$ value and consequently largest number of sites for As(V) adsorption (Table 6 and Figure 5). 


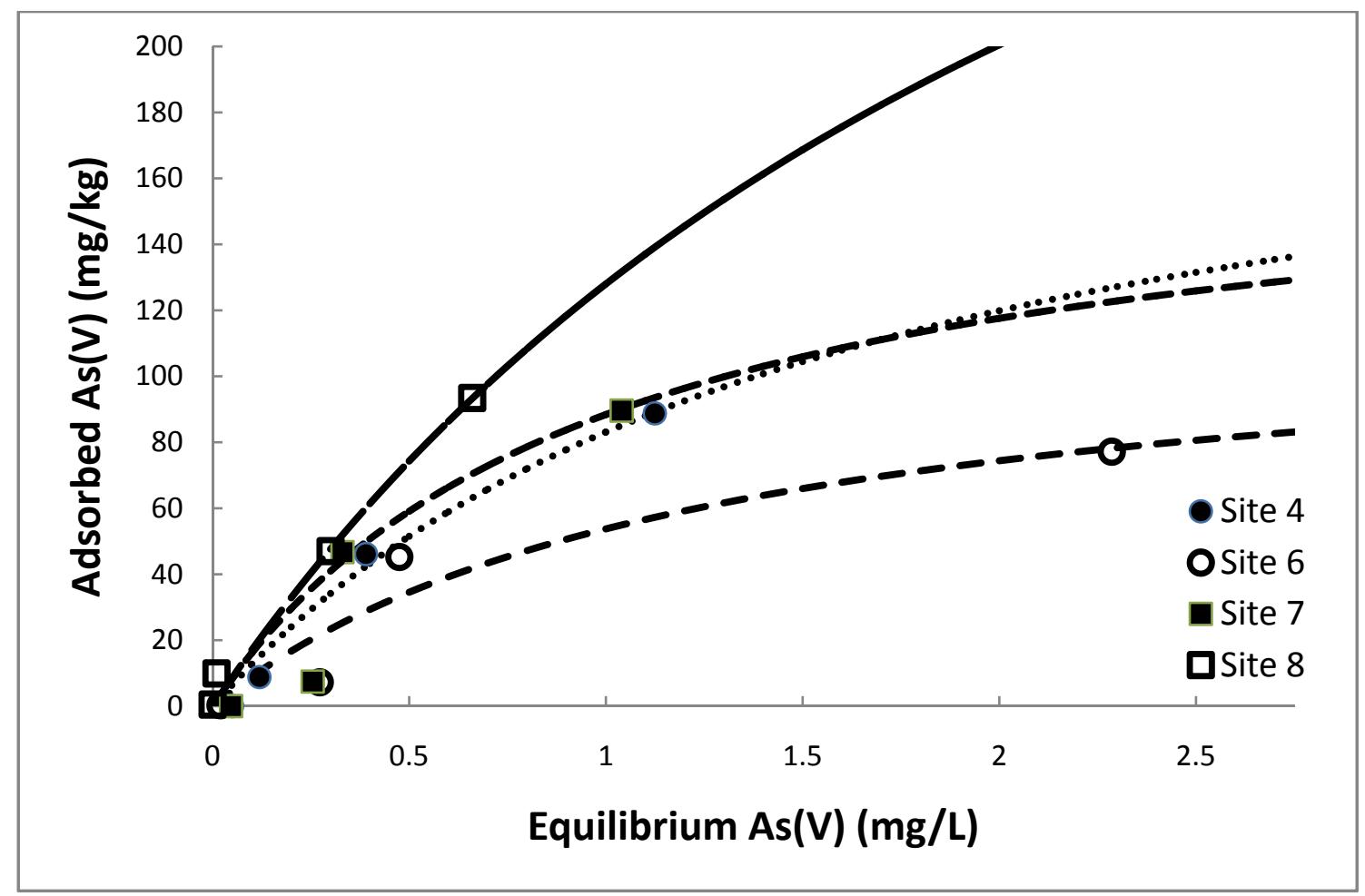

Figure 5. Experimental $\mathrm{As}(\mathrm{V})$ adsorption as a function of equilibrium concentration. Dashed lines represent Langmuir model fitted to experimental data using nonlinear least squares regression.

Table 6. Langmuir Isotherm parameters derived from adsorption experiments

\begin{tabular}{cccc}
\hline Sample & $\mathbf{K}(\mathbf{L} / \mathbf{m g})$ & $\mathbf{S}_{\mathbf{t}}(\mathbf{m g} / \mathbf{K g})$ & $\mathbf{R}^{2}$ \\
\hline Site 4 & 0.63 & 215 & 0.981 \\
Site 6 & 0.92 & 104 & 0.901 \\
Site 7 & 1.01 & 175 & 0.982 \\
Site 8 & 0.38 & 462 & 0.987 \\
\hline
\end{tabular}




\subsection{Acidification Experiments}

Table 7 shows the results of the batch acidification experiments as a potential remediation scheme. The most significant change in $\mathrm{As}(\mathrm{V})$ concentrations occurs in Site 4 with a $63 \%$ decrease at $\mathrm{pH} 7.3$ relative to the control. At this location, the control (no acidification) had 460 $\mu \mathrm{g} \mathrm{L} \mathrm{L}^{-1}$ As at $\mathrm{pH} 8.4$ while the treated samples at $\mathrm{pH} 7.7$ and 7.3 had $\mathrm{As}(\mathrm{V})$ levels of 269 and 170 $\mu \mathrm{g} / \mathrm{L}$ respectively. For Sites 6 , a $50 \%$ decrease in $\mathrm{As}(\mathrm{V})$ concentration was observed at $\mathrm{pH} 7$. At site 7 however, $\mathrm{As}(\mathrm{V})$ levels did not significantly change and remained relatively stable down to pH $7(<10 \%$ decrease $)$.

The relatively insignificant changes observed in Site 7 (from 545 to $509 \mu \mathrm{g} \mathrm{L}^{-1}$ ) in the $\mathrm{pH}$ range of 8.4 to 7 could be related to the significantly higher concentrations of phosphate acting as a competing ion in the groundwater from this site and therefore inhibiting the $\mathrm{As}(\mathrm{V})$ sorption. Groundwater from Site 8 was already at relatively much lower initial dissolved As(V) concentrations $\left(13 \mu \mathrm{g} \mathrm{L}^{-1}\right)$ that underwent further removal by lowering the $\mathrm{pH}\left(2 \mu \mathrm{g} \mathrm{L}^{-1}\right)$.

The substantial increase in dissolved $\mathrm{Ca}$ concentrations in Sites 4 and 6 indicates that the dissolution of calcite minerals, known to be present at these two sites, is occurring. At Site 7 however, the dissolved $\mathrm{Ca}$ increased very moderately in agreement with the lower level of $\mathrm{pH}$ buffering observed.

Table 7. Acidification Experiment Results (All concentrations in $\mathrm{mg} \mathrm{L}^{-1}$ )

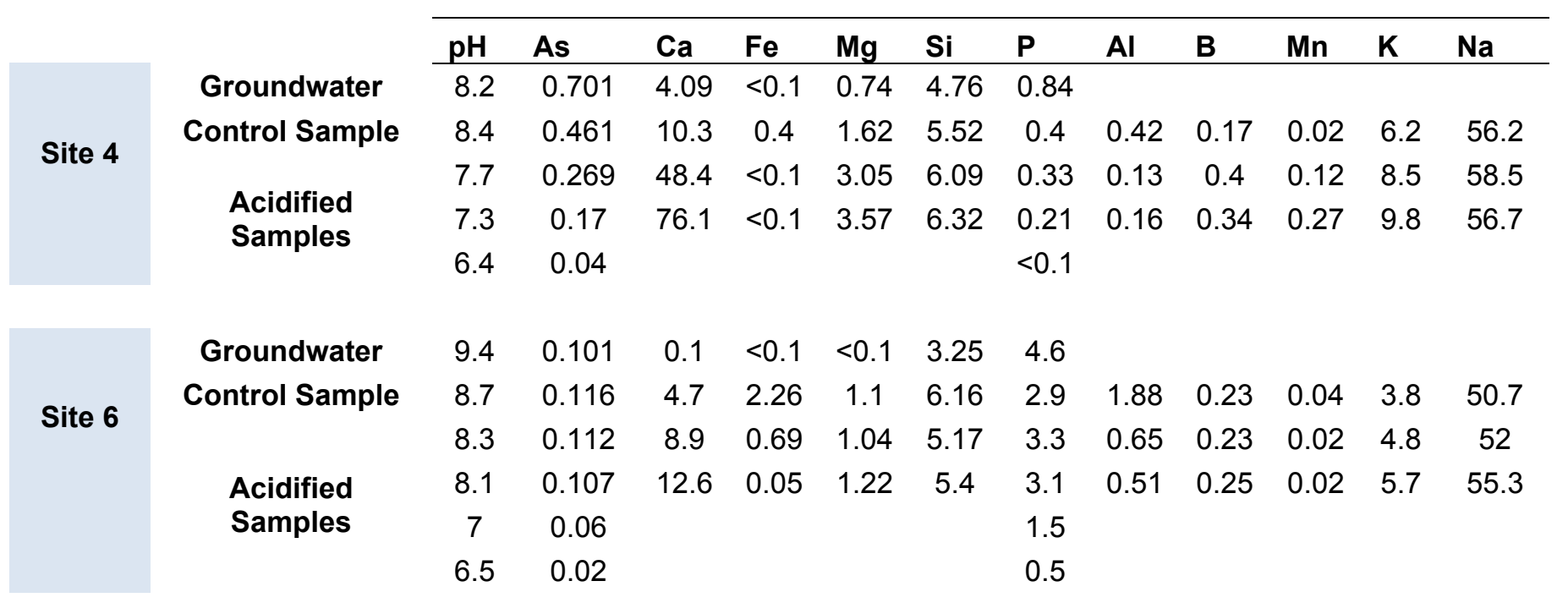




\begin{tabular}{|c|c|c|c|c|c|c|c|c|c|c|c|c|c|}
\hline \multirow{5}{*}{ Site 7} & Groundwater & 7.9 & 0.536 & 1.6 & $<0.1$ & 0.32 & 9.01 & 7.5 & & & & & \\
\hline & Control Sample & 8.4 & 0.545 & 1.9 & 1.53 & 0.5 & 11.5 & 8.9 & 0.86 & 1.03 & 0.09 & 4 & 120.3 \\
\hline & & 7.7 & 0.525 & 2.2 & 2.06 & 0.63 & 13.3 & 8 & 1.17 & 1.03 & 0.09 & 6.5 & 127.8 \\
\hline & $\begin{array}{l}\text { Acidified } \\
\text { Samnles }\end{array}$ & 7 & 0.509 & 2.3 & 2.45 & 0.74 & 14.3 & 7.5 & 1.8 & 1.18 & 0.11 & 5.1 & 124.8 \\
\hline & & 6.1 & 0.461 & & & & & 6.9 & & & & & \\
\hline \multirow{4}{*}{ Site 8} & Groundwater & 7 & $<0.008$ & 49.6 & $<0.1$ & 13.2 & 8.56 & $<0.1$ & & & & & \\
\hline & Control Sample & 8.3 & 0.013 & 49.6 & $<0.1$ & 12.2 & 8.81 & $<0.2$ & 0.04 & 0.13 & 0 & 4.2 & 26 \\
\hline & Acid & 7.5 & 0.006 & 50.4 & $<0.1$ & 12.6 & 9.6 & $<0.2$ & 0.04 & 0.14 & 0.03 & 6.2 & 25.9 \\
\hline & Samples & 6.8 & 0.002 & 51.1 & $<0.1$ & 12.9 & 9.13 & $<0.2$ & 0.07 & 0.11 & 0.05 & 5.3 & 26.1 \\
\hline
\end{tabular}

\subsection{Acid Titration Results}

Different levels of pH-buffering were observed during the acidification experiments. Site 4 had the highest buffering capacity followed by Sites 6 and 7. Similarly, during acid titration experiments, sediment and the sediment-groundwater mixture for Site 4 exhibited a significantly larger buffering capacity, which is also supported by presence of significant calcite pool evident in acidification experiments (Figure 6). Spikes seen in Figure 6 for Site 4 are likely due to outgassing of carbon dioxide from samples overnight.

For groundwater, while having a similar initial $\mathrm{pH}$ as Site 4, groundwater in Site 7 exhibited a somewhat higher level of buffering. This is in agreement with the higher alkalinity measured at Site 7 groundwater $\left(150 \mathrm{mg} \mathrm{L}^{-1}\right.$ as $\left.\mathrm{CaCO}_{3}\right)$ compared to Site $4\left(100 \mathrm{mg} \mathrm{L}^{-1}\right.$ as $\left.\mathrm{CaCO}_{3}\right)$. These results suggest that the overall more significant $\mathrm{pH}$-buffering evident in Site 4 is mostly due to the solid phase reactions such as carbonates dissolution, whereas in Site 7 buffering is mainly controlled by the reactions in the aqueous phase. 

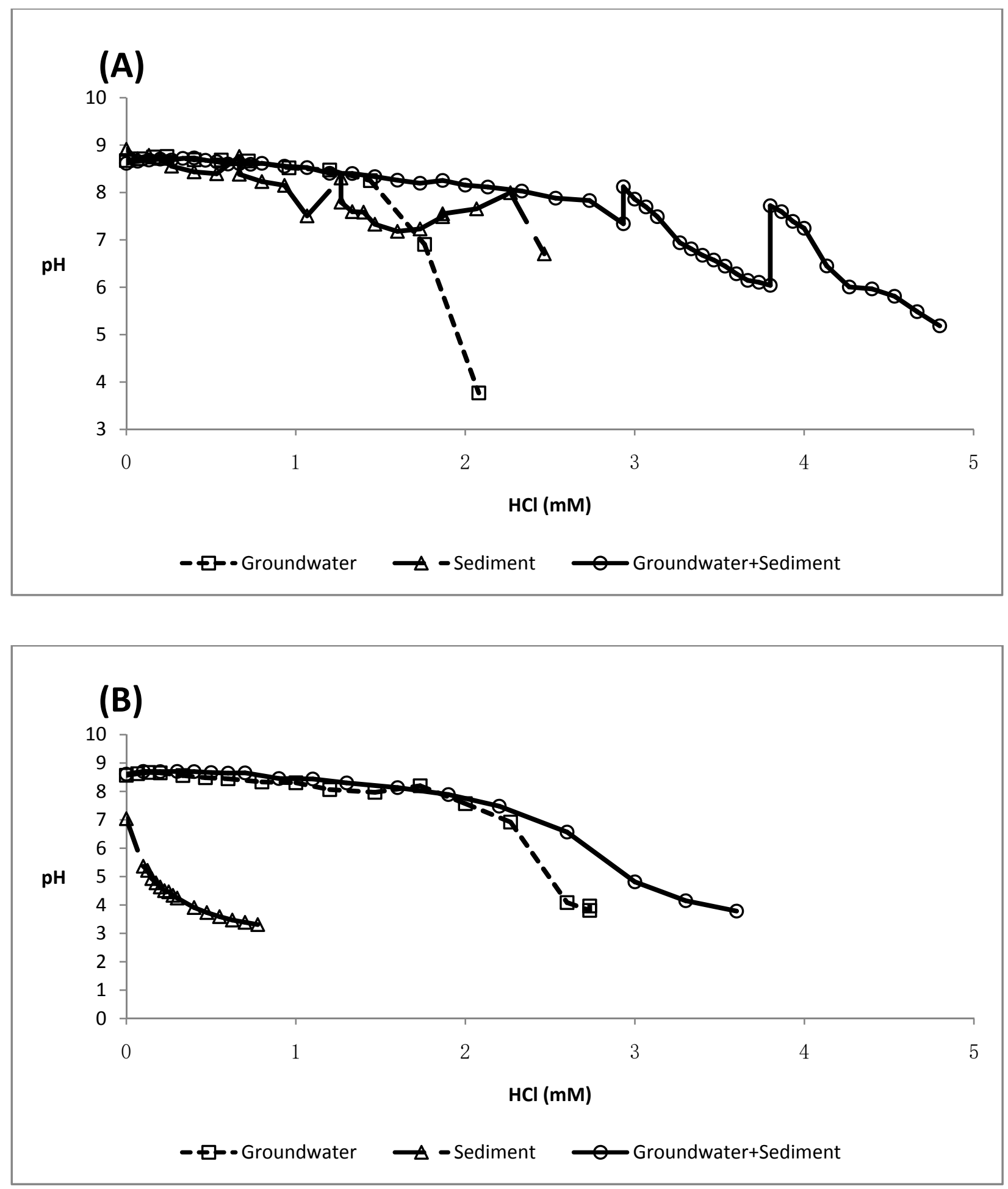


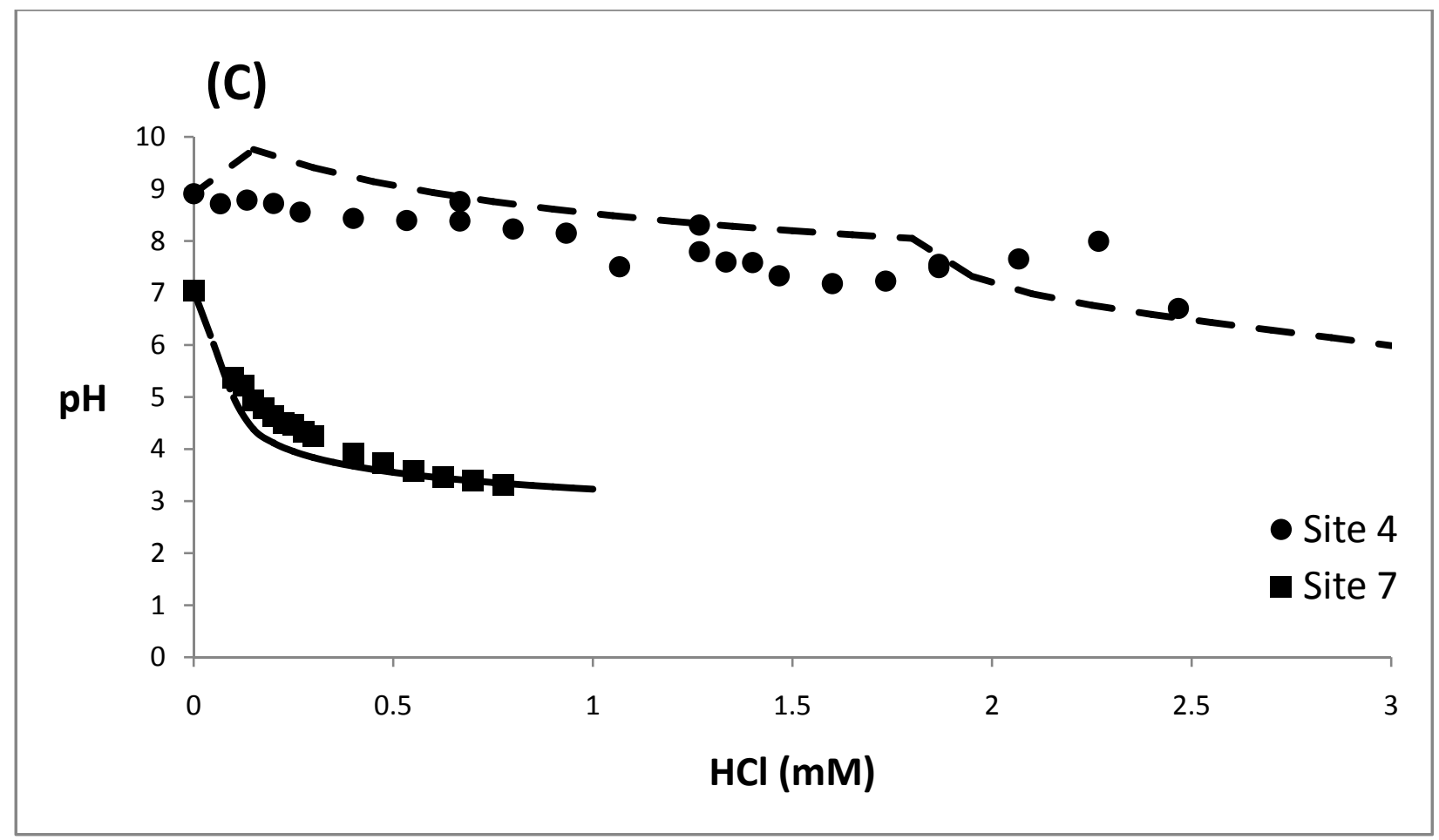

Figure 6. Acid titration experimental results for (A) Site 4, (B) Site 7. Experimental and modeling results (dashed lines) for $\mathrm{pH}$ buffering of sediments (C).

\subsection{Geochemical Modeling Results}

\subsubsection{Thermodynamic and buffering calculations}

Aqueous speciation by PHREEQC indicates that As is mainly present as the arsenate oxyanions $\mathrm{H}_{2} \mathrm{AsO}_{4}^{-}$andHAsO $\mathrm{O}_{4}^{2-}$ which is expected for an oxic groundwater in the $\mathrm{pH}$ range studied here. Calculated saturation indices (SI) by PHREEQC indicated that the solutions for all sites are undersaturated with respect to common As bearing minerals and metal arsenates indicating that such phases will not possibly form by precipitation from solution.

Fe (III) oxides, ferrihydrite, goethite and hematite are found to be all supersaturated in the studied sites with assumption of an oxidizing environment based on the field data (pe $=4$ ). Nevertheless, in the lack of sufficient kinetic data it cannot be postulated that any of these phases will be precipitated. The calculated SI values indicate that the system in Site 7 with noticeable phosphate concentrations $\left(8.9 \mathrm{mg} \mathrm{L}^{-1}\right)$ is supersaturated with respect to several apatite minerals 


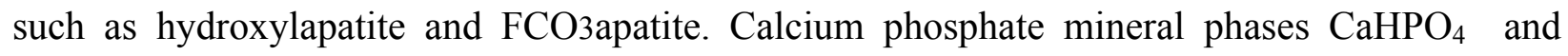
$\mathrm{Ca}_{3}\left(\mathrm{PO}_{4}\right)_{2}$, however, have SI values closer to zero, indicating equilibrium

PHREEQC was also used to model the solid phase pH buffering in Sites 4 and 7 and the models fit the experimental data reasonably well (Figure 6).

\subsubsection{Acidification simulation}

Models for the selected sampling locations (Sites 4, 6, 7 and 8) built in PHREEQC used surface site densities derived from adsorption isotherms, two different chemical extractions of amorphous Fe oxides, and BET surface area measurements. The goodness of fit of the model predictions to experimental data was quantified by calculating the normalized root mean square error (NRMSE):

$$
N R M S E=\sqrt{\frac{\sum\left(\frac{C_{\text {exp }}-C_{\text {mod }}}{C_{0}}\right)^{2}}{n_{\text {exp }}}}
$$

where, $\mathrm{C}_{\exp }$ is the measured aqueous concentration, $\mathrm{C}_{\text {mod }}$ is the simulated aqueous concentration, $\mathrm{C}_{0}$ is the initial aqueous concentration, and $\mathrm{n}_{\exp }$ is the number of experimental data points.

Results of the different model simulations for As and phosphate concentrations are illustrated in Figure 7. Table 8 lists the NRMSE values for model fits. 

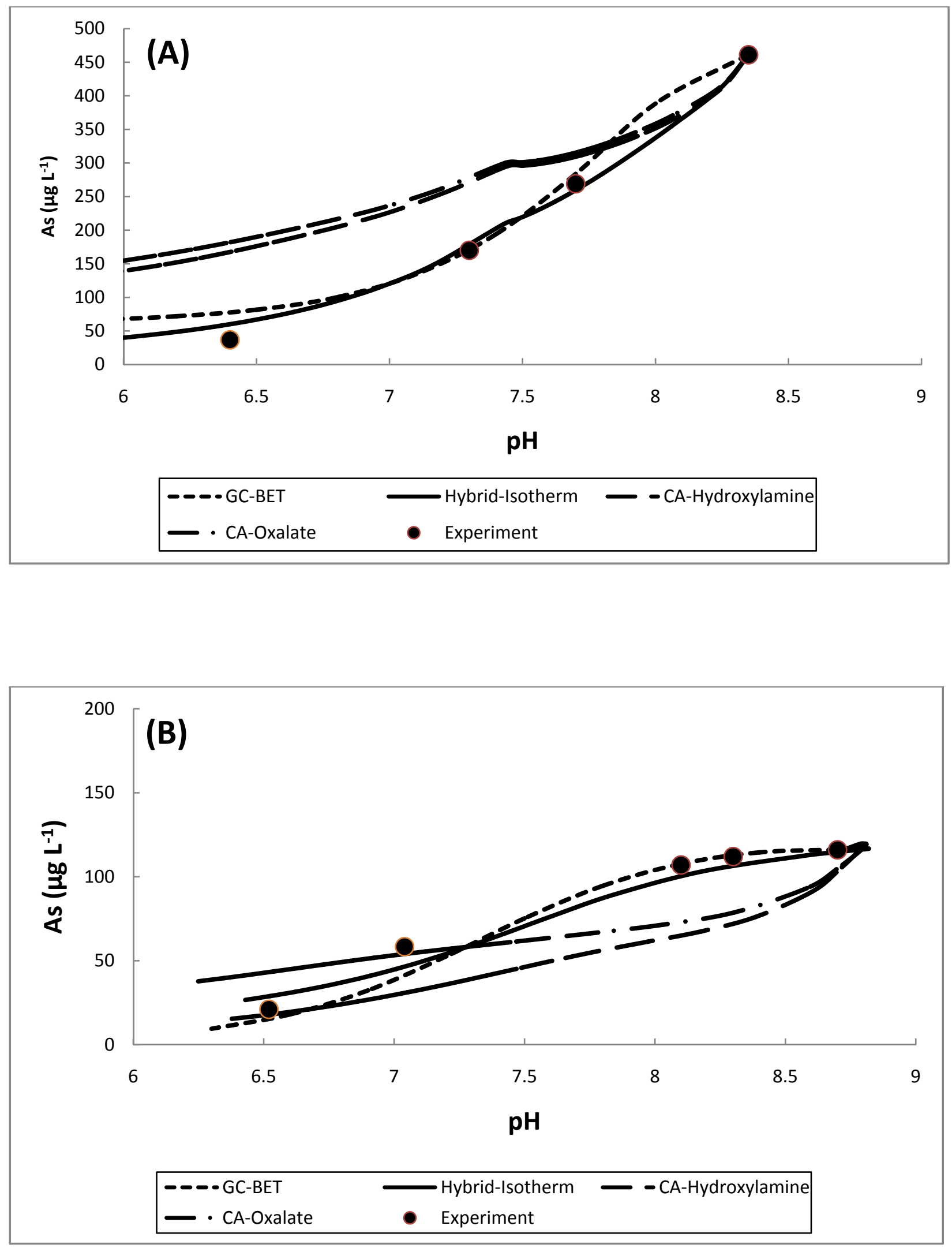

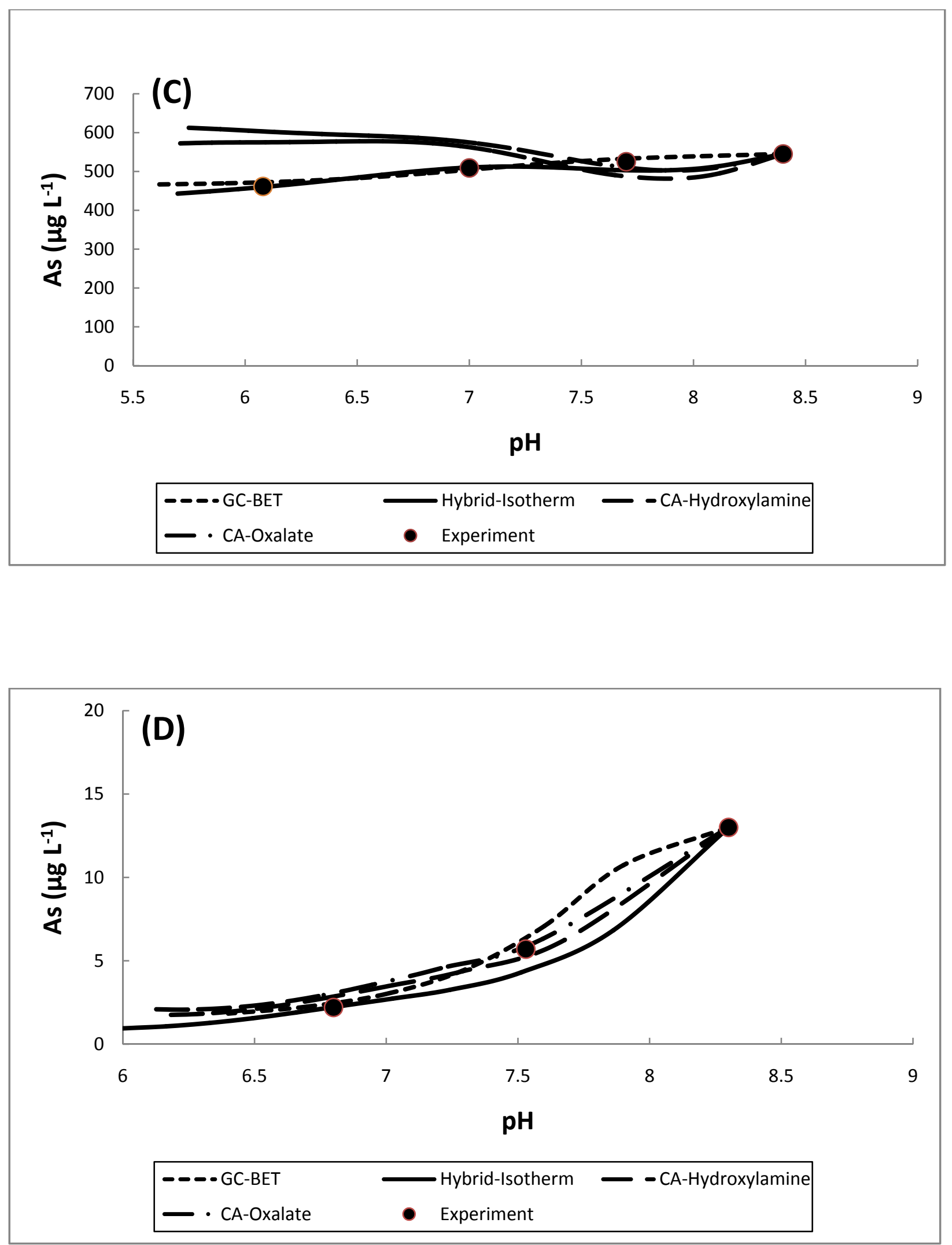


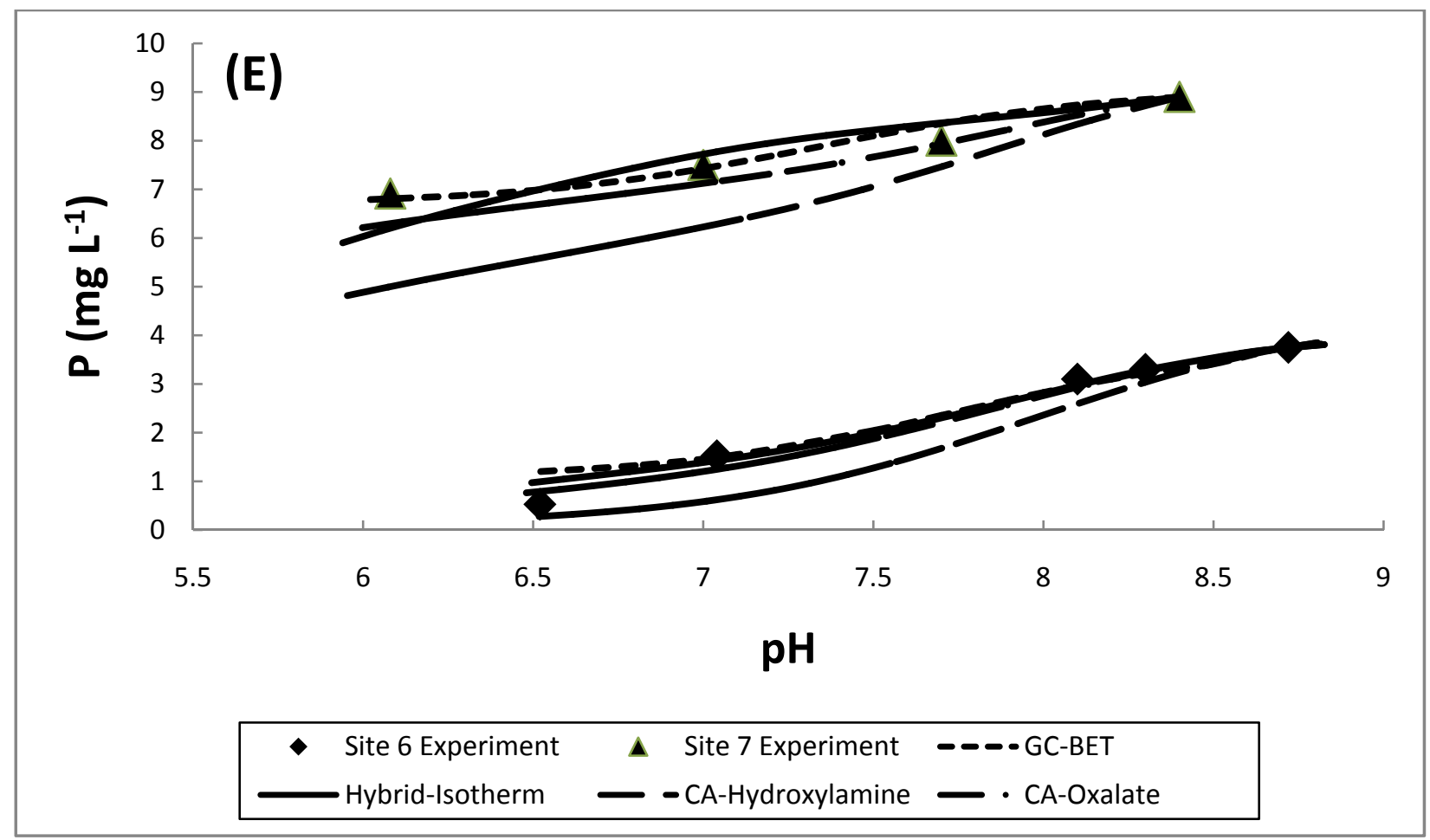

Figure 7. Dissolved $\mathrm{As}(\mathrm{V})$ in acidification experiments compared with the modeling simulations for (A) Sites 4, (B) Site 6, (C) Site 7, and (D) Site 8. Dissolved phosphate concentrations in acidification experiments compared with the modeling simulations for (E) Sites 6 and 7.

Table 8. Comparison of the goodness of fit values (NRMSE, \%) for different model simulations of acidification experiments

\begin{tabular}{lcccccc}
\hline & Site 4 & \multicolumn{2}{c}{ Site 6 } & \multicolumn{2}{c}{ Site 7 } & Site 8 \\
Model & $\mathrm{As}(\mathrm{V})$ & $\mathrm{As}(\mathrm{V})$ & $\mathrm{PO} 4$ & $\mathrm{As}(\mathrm{V})$ & $\mathrm{PO4}$ & $\mathrm{As}(\mathrm{V})$ \\
\hline CA-Hydroxylamine & 18.5 & 24.6 & 13.1 & 12.0 & 13.3 & 3.0 \\
CA-Oxalate & 20.3 & 20.3 & 5.0 & 14.4 & 4.1 & 4.1 \\
GC-BET & 4.8 & 6.7 & 8.2 & 1.3 & 2.1 & 3.7 \\
Hybrid-Isotherm & 2.9 & 6.5 & 5.8 & 1.9 & 4.7 & 4.9 \\
\hline
\end{tabular}


The CA-Hydroxylamine and CA-Oxalate models underestimate the sorption of As in Site 4 while overestimating the results in Site 6 for the higher $\mathrm{pH}$ ranges. Bigger disagreement between these two models and experimental data exist in Site 7 where the CA model predictions show increase in dissolved $\mathrm{As}(\mathrm{V})$ concentration instead of the slight decreasing trend of $\mathrm{As}(\mathrm{V})$ observed. In Site 8, due to the low initial concentration of $\operatorname{As}(\mathrm{V})$ and lack of significant adsorption competition, all models exhibit similar trends and yield reasonably good fits with the data. The CA-Oxalate model yields good fits (NRMSE $<5 \%$ ) to phosphate data in Sites 6 and 7 (Figure 7e) while the CA-Hydroxylamine model overestimates the adsorption at most $\mathrm{pH}$ values. The Hybrid-Isotherm and GC-BET models exhibit moderate to good agreements in fitting the experimental $\mathrm{As}(\mathrm{V})$ and phosphate data in all sites.

Table 9 lists the adjusted surface reaction constants for -Hybrid-Isotherm model in comparison to the default values for HFO database. It can be noted that only the two reactions for the negatively charges surface species needed to be modified and the reaction constant for the neutral Assurface species was not modified in any of the sites as this reaction is only important at the lower range of $\mathrm{pH}$ values.

Table 9. Surface complexation reaction constants for A) modified in Hybrid-Isotherm model B) optimized by FITEQL in GC-BET model. The bold values represent the modified constants.

\begin{tabular}{|c|c|c|c|c|c|}
\hline & Default & Site 4 & Site 6 & Site 7 & Site 8 \\
\hline \multicolumn{6}{|l|}{ Arsenate } \\
\hline Hfo_w $\mathrm{w}_{2} \mathrm{AsO}_{4}$ & 8.61 & 8.61 & 8.61 & 8.61 & 8.61 \\
\hline $\mathrm{Hfo}_{-} \mathrm{sHAsO}_{4}^{-}$ & 2.81 & 3.8 & 3.6 & 2.9 & 3.7 \\
\hline $\mathrm{Hfo}_{-} \mathrm{wOHAsO}_{4}{ }^{-3}$ & -10.12 & -10.12 & -11.5 & -10.5 & -10.12 \\
\hline \multicolumn{6}{|l|}{ Phosphate } \\
\hline $\mathrm{Hfo} \_w H 2 \mathrm{PO}_{4}$ & 31.29 & 31.29 & 32.5 & 31.29 & 31.29 \\
\hline Hfo_wHPO ${ }_{4}^{-}$ & 25.39 & 24.5 & 25.7 & 23.5 & 25.39 \\
\hline Hfo_WPO${ }_{4}^{-2}$ & 17.72 & 17.72 & 17.72 & 19.1 & 17.72 \\
\hline
\end{tabular}




\begin{tabular}{|c|c|c|c|c|}
\hline & Site 4 & Site 6 & Site 7 & Site 8 \\
\hline \multicolumn{5}{|l|}{ Arsenate } \\
\hline Site_zH2AsO & - & - & - & - \\
\hline Site_z $z \mathrm{HAsO}_{4}^{-}$ & 6.91 & 7.66 & 6.43 & 8.7 \\
\hline Site_zAsO ${ }_{4}^{-2}$ & - & - & -0.81 & - \\
\hline Site_zOHAsO $4^{-3}$ & -9.93 & -9.34 & -10.58 & -7.72 \\
\hline \multicolumn{5}{|l|}{ Phosphate } \\
\hline Site_z $z \mathrm{H}_{2} \mathrm{PO}_{4}$ & & - & - & \\
\hline Site_z $\mathrm{HPO}_{4}^{-}$ & & 27.89 & 26.9 & \\
\hline Site_z $\mathrm{PO}_{4}{ }^{-2}$ & & 17.14 & 18.87 & \\
\hline
\end{tabular}

The Hybrid-Isotherm models were capable of adequately simulating the adsorption of $\operatorname{As}(\mathrm{V})$ in all four sites. The different rates of modeled $\operatorname{As}(\mathrm{V})$ removal among the studied sites were strongly influenced by the magnitude of phosphate concentrations present and the consequent competition for sorption sites. This was verified by calculating and comparing the distribution of surface species in equilibrium with the groundwater. Figure 8 shows the calculated distribution of surface species by Hybrid-Isotherm model for Sites 4 and 7 at $\mathrm{pH} 7$. In Site 7, about $98 \%$ of available sorption sites are occupied by other solutes, mainly competing ions $\mathrm{PO}_{4}, \mathrm{Si}$ and $\mathrm{CO}_{3}$. In Site 4 however, $\operatorname{As}(\mathrm{V})$ outcompetes the much lower level of phosphate present, occupying 12\% of surface sites which corresponds to the higher level of $\mathrm{As}(\mathrm{V})$ adsorption observed experimentally. 
(A)

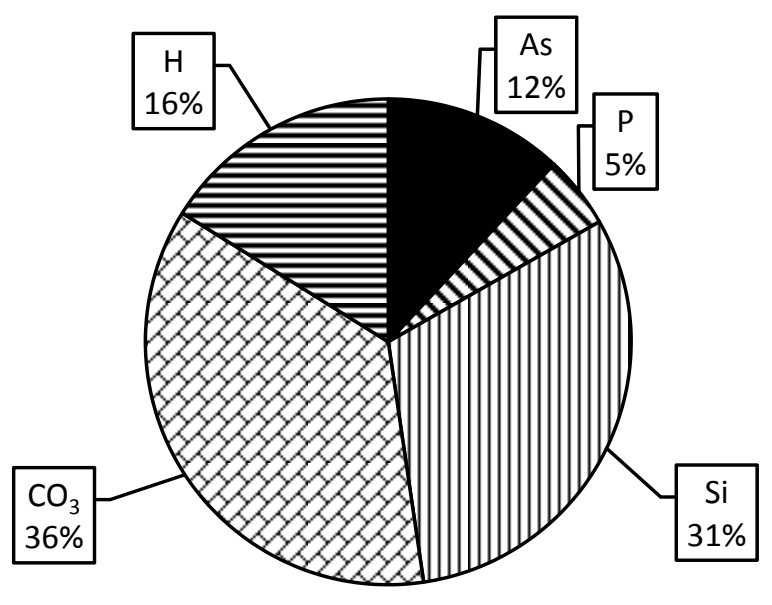

(B)

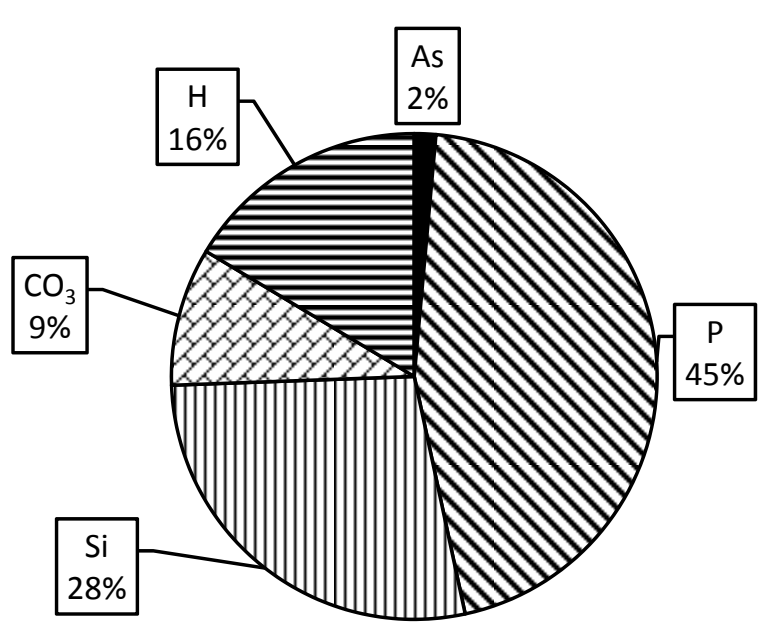

Figure 8. Simulated distribution (\%) of surface species at $\mathrm{pH} 7$ for (A) Site 4, (B) Site 7.

The field for each parameter in the pie chart is the sum of all surface species associate with the solute.

Due to the surface reaction constants being sensitive to the total surface site number used and the fact that values derived from the BET method were significantly larger than the value estimated from other methods, FITEQL was utilized for the GC-BET models in order to obtain a quantitative goodness of fit for the fitted $\mathrm{K}$ values. The indicator for how well the experimental data are fitted is the weighted sum of squares of residuals divided by degrees of freedom (WSOS/DF) with the value of between 0.1 and 20 considered a good fit achieved in all cases. 
It must be noted that all the surface reactions for complexation of other solutes with HFO were excluded from the input in the GC-BET models as these reactions and their log K values are only valid for adsorption on ferrihydrite surface $\left(600 \mathrm{~m}^{2} / \mathrm{g}\right)$ with a diffuse double layer model and assumed density of 0.2 moles sites per mole Fe. Therefore the fitted constants for As adsorption in GC-BET models are considered specific to the sediments studied and the total concentration of competing ions present. In the case of Site 6 and 7, surface reactions and species for complexation of dissolved phosphate were also included in the optimization process using FITEQL. Derived reaction constants from FITEQL used in the GC-BET models are displayed in Table 9. With the exception of Site 7, in all cases only two surface reactions were needed to model the data. Similar to the Hybrid-Isotherm models, the neutrally charged surface species had no influence on fitting the data as the formation of negatively charged species are more important in the $\mathrm{pH}$ range studied. There are currently very scarce reaction constant values reported for natural oxidized sediments for direct comparison with the derived constants in this study.

\section{Discussion}

\subsection{Acidification as a Remediation Strategy}

While acidification in Site 4 produced the highest removal rates, the $\mathrm{As}(\mathrm{V})$ concentration at $\mathrm{pH} 7$ was still significantly higher than the EPA standard limit of $10 \mu \mathrm{g} \mathrm{L} \mathrm{L}^{-1}$. Sites 6 and 7 with high $\mathrm{As}(\mathrm{V})$ concentrations achieved moderate to minor decline in aqueous levels.

The acidification experiment results exhibit lower levels of $\mathrm{As}(\mathrm{V})$ retention on sediments with increasing levels of phosphate in solution. There are significantly higher levels of phosphate present in Site 6 and 7 groundwater which results in sorbed phosphate concentrations exceeding the sum of sorbed $\mathrm{As}(\mathrm{V})$ species and therefore limiting the overall As(V) removal rates. The experimental and modeling results agree that acidification alone will not be an effective remediation method for controlling the aqueous $\mathrm{As}(\mathrm{V})$ levels and needs to be implemented in combination with other approaches.

\subsection{Surface Complexation Modeling}


The CA-Hydroxylamine and CA-Oxalate models yield very similar results due to their comparable values of derived surface site densities. Using the default database reaction constants, the CA models are able to predict the general trend of experimental data in Site 4 and 8. However the CA models do not yield a good fit to As(V) data in Site 6 and 7 where multicomponent adsorption (competition with $\mathrm{PO}_{4}, \mathrm{CO}_{3}, \mathrm{SiO}_{4}$ ) becomes important and experimental results do not show appreciable changes in the $\mathrm{As}(\mathrm{V})$ concentrations. The Fe extraction based model, CA-Hydroxylamine overestimates the As(V) adsorption in Site 6 by about 50\%, and predict desoprtion of As below $\mathrm{pH} 7.5$ in Site 7. These results show the limited predictive application of CA models in more complex systems with a larger number of variables present.

The DDL database (Dzombak and Morel, 1990) contains three reactions for describing the sorption of $\mathrm{As}(\mathrm{V})$ on HFO but it does not include the constant for reaction resulting in formation of doubly negative charged species $\left(\mathrm{Hfo}_{-} \mathrm{AsO}_{4}{ }^{-2}\right.$ ) as it was indicated to be not effective in improving the fitting of data. The analogous reaction for formation of (Site_zAsO ${ }_{4}^{-2}$ ) was included in the non-electrostatic GC-BET models in this study and it was found to improve the model fit significantly in Site 7 where highest level of competitive adsorption was present. However, including it in the other models did not have any impact on the goodness of fit and therefore it was omitted.

Since the surface complexation constants in the GC-BET models are fitted to the experimental data at $\mathrm{pH}$ values $>7$ and do not include the uncharged complexes, the resulting models will not be capable of predicting $\mathrm{As}(\mathrm{V})$ or phosphate adsorption at lower $\mathrm{pH}$ values where these surface complexes become important. On the other hand, the Hybrid-Isotherm models which include the unchanged reaction constants from DDL database for these uncharged complexes, can be used for obtaining predictions in the lower $\mathrm{pH}$ range but their performances need to be further evaluated.

It should be noted that the equilibrium constants for the analogous surface reactions and species should not be directly compared between the Hybrid-isotherm and GC-BET models as there are wide differences between the values of total surface site concentration used in the two models. The choice of determining the number of surface sites affects the resulting reaction constants significantly. Also, the $\mathrm{pH}$ dependence of adsorption is simulated differently between the two models as the Hybrid-Isotherm model incorporates the HFO surface acidity constants and the 
DDL theory, but the GC-BET model compensates for the absence of these factors by changing the distribution of surface speciation as a function of $\mathrm{pH}$.

\subsection{Comparison of Methods for Determining the Adsorption Capacity of Sediments}

Quantification of the total number of surface sites is an essential component of any SCM. There is an inherent difficulty in accurately determining the relative abundance of sorbent constituents of a heterogeneous mixture and such data are rarely available for describing the retention of solutes by sediments. In this study, four different methods for calculating the concentration of total sorption sites for use in the models were implemented (Figure 9). These methods include using the Langmuir $\mathrm{S}_{\mathrm{t}}$ parameter, two extraction methods aimed at dissolving amorphous iron oxides, and the BET surface area measurement.

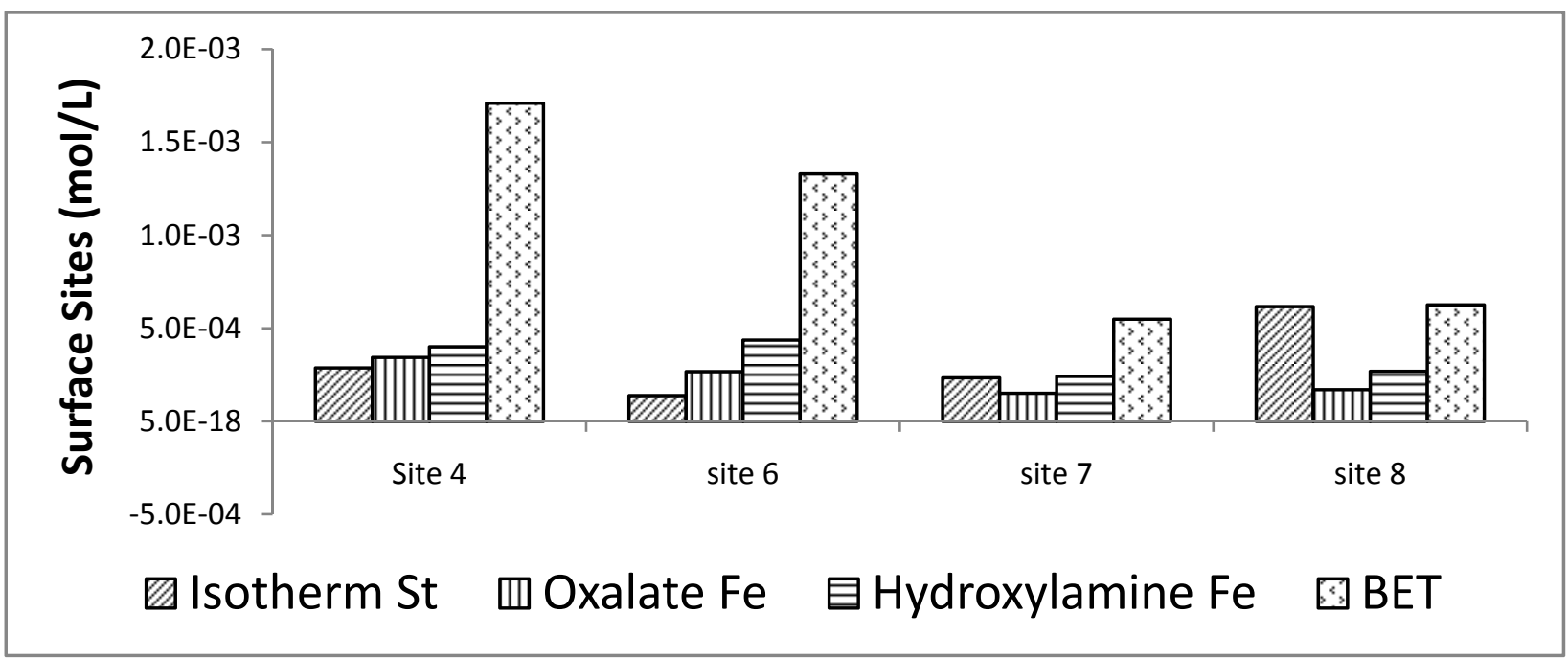

Figure 9. Surface site concentration calculated from four different methods; $\mathrm{S}_{\mathrm{t}}$ from the Langmuir adsorption isotherm, Fe concentration extracted by oxalate, Fe concentration extracted by hydroxylamine hydrochloride, and BET surface area measurement.

The method of using the $S_{t}$ parameter from the empirical Langmuir isotherm model in developing a mechanistic SCM seems promising since it could be used as a normalizing measure for determining the maximum number of sorption sites not exclusive to any specific sorbent solid phases. In this method, the maximum sorption capacity for $\mathrm{As}(\mathrm{V}),\left(\mathrm{S}_{\mathrm{t}}\right)$ is converted to moles of sorption sites by assuming a 1:1 molar ratio between As and sorption sites. This values is then 
normalized to the solid/solution ratio and converted to moles of HFO by using the density of 0.2 sites/mol HFO (Dzombak and Morel, 1990).

Compared to the other estimation methods, using the adsorption isotherm could minimize the risk of overestimation of available surface sites by not including the sites pre-occupied by other adsorbates. Using $\mathrm{S}_{\mathrm{t}}$ could also avoid potential underestimation by acting as a pool for the contribution of all reactive sorption sites and not just considering certain phases as is the case with extraction methods. Nonetheless, interpretation of adsorption isotherm results could be difficult to definitively determine what general shape they follow. Another difficulty is determining whether the isotherm has reached maximum monolayer surface coverage or surface precipitation is occurring and being responsible for the observed sorption. As the concentration of dissolved solute increases, the mechanism transitions from surface adsorption to surface precipitation. Consequently, the choice of maximum concentration of solute in an adsorption isotherm experiment becomes important as it could also be a factor in underestimating or overestimating the sorption site density.

A number of the published studies have used chemical extraction of poorly crystalline Fe oxides as the method for determining the surface site densities of sorbents used in SCM (Jung et al., 2012; Robinson et al., 2011; Sharif et al., 2011). The assumption used is that the Fe oxide phases are principally responsible for the sorption of solutes.

With the exception of the un-impacted Site 8, the extraction and isotherm methods result in relatively similar number of sites and values are in the same order of magnitude. In the upgradient contaminated sites, Langmuir St estimation gives the smallest value relative to other methods, suggesting that the sorption sites are already occupied to some extent by As or other solutes in the plume. Therefore, using Fe concentrations from chemical extractions as often done in the published studies, could lead to potential overestimation of adsorption results if not taking into consideration the sites previously occupied by adsorbates and/or not reactive with regard to the solute of interest.

The Langmuir isotherm and BET surface area derived values generally represent the contribution of all of the sorptive surfaces as opposed to the selective extractions targeting specific phases such as amorphous Fe oxides. The isotherm derived value for Site 8 is much larger than values 
from extraction methods and slightly smaller than the BET derived number. This suggests that the un-impacted Site 8 has significantly larger number of available surface sites for As adsorption which are not only attributed to amorphous Fe oxides but also to other sorptive phases present in the solid matrix. This indicates that selective extraction methods could also lead to underestimation of adsorption results in these aquifer sediments by neglecting the other available adsorbent phases.

Characterization of the aquifer sediments with respect to ability for re-adsorbing As is of critical importance if efforts for remediation of As at this site are to be considered. Although sequential extractions data show close similarities between the solid phase distribution and total content of As between Sites 7 and 8, Site 8 exhibits more than a 2 fold higher number of total adsorption sites $\left(\mathrm{S}_{\mathrm{t}}\right)$. A combination of induced geochemical changes due to high $\mathrm{pH}$ waste plume and occupation of active surface sites by competing ions could be responsible for the significantly lower adsorption sites in Site 7.

In the contaminated sites ( 4,6 and 7), the determination of surface sites based on BET surface area measurements results in significantly larger values than those derived from the Langmuir $\mathrm{S}_{\mathrm{t}}$. However, in the un-contaminated Site 8, the BET and Langmuir St derived values are very close. This suggests that the maximum surface site given by the BET measurement has been diminished in the historically contaminated zone and only a fraction of sites are available for adsorption of $\operatorname{As}(\mathrm{V})$.

\subsection{Application of Models}

The SCM simulations are strongly influenced by the amount of total surface sites assigned in the models (HFO or generic sites). Although the competing ions concentrations at Site 4 are relatively lower than Sites 6 and 7, the number of surface sites is still not sufficient to decrease $\mathrm{As}(\mathrm{V})$ in the liquid phase to the regulatory levels.

Only few studies have used SCM tools to study the natural attenuation and effectiveness of using stabilizing amendments for metal contaminated sites (Komarek et al., 2013). In particular, there is also a lack of data available in the literature from applications of geochemical modeling for remediation of As contaminated environments (Moldovan et al., 2005). 
The developed Hybrid-Isotherm models for simulating the acidification experiments in PHREEQC were subsequently used to assess several potential schemes of As remediation by acidification and promoted natural attenuation (Figure 10). Site 4 acidification model was modified by using the solid characteristics of un-impacted Site 8 . This alteration and increase in the number of sorption sites $\left(\mathrm{S}_{\mathrm{t}}\right)$ in addition to lowering the $\mathrm{pH}$ resulted in significant improvement of $\mathrm{As}(\mathrm{V})$ removal. This method achieved desirable As levels below the standard drinking water limits at $\mathrm{pH}$ 7.5. However the strategy of equilibrating the groundwater with Site 8 solid phase did not achieve the same results in Sites 6 and 7. At these two sites, in order to decrease $\mathrm{As}(\mathrm{V})$ concentration to desirable levels within a practical $\mathrm{pH}$ range, dissolved phosphate concentrations also had to be lowered to $1 \mathrm{mg} \mathrm{L}^{-1}$ prior to acidifying the solution.

Developed models in this study will be applied in reactive transport modeling of future column studies to study the transport of $\mathrm{As}(\mathrm{V})$ in both contaminated and un-contaminated zones.

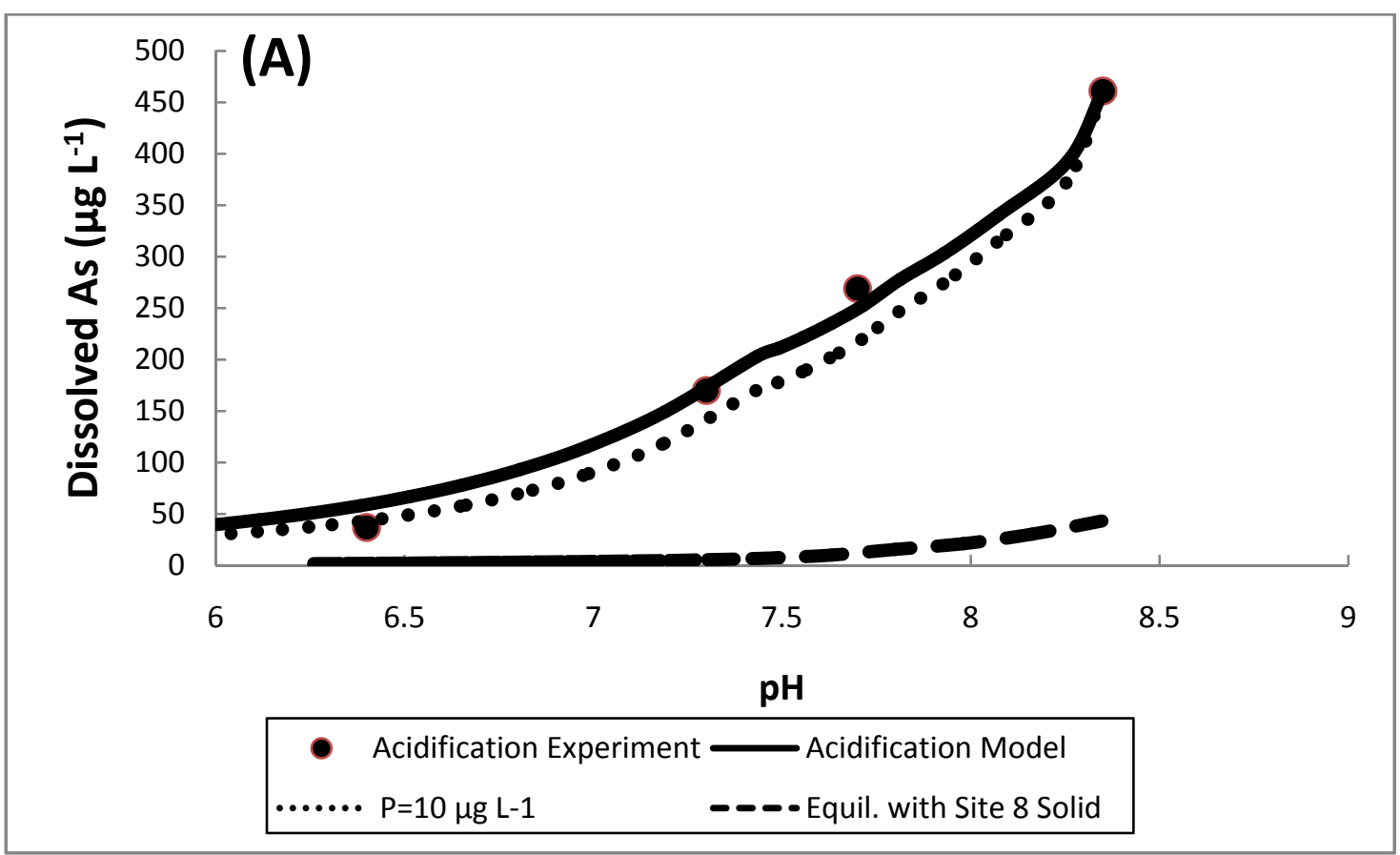



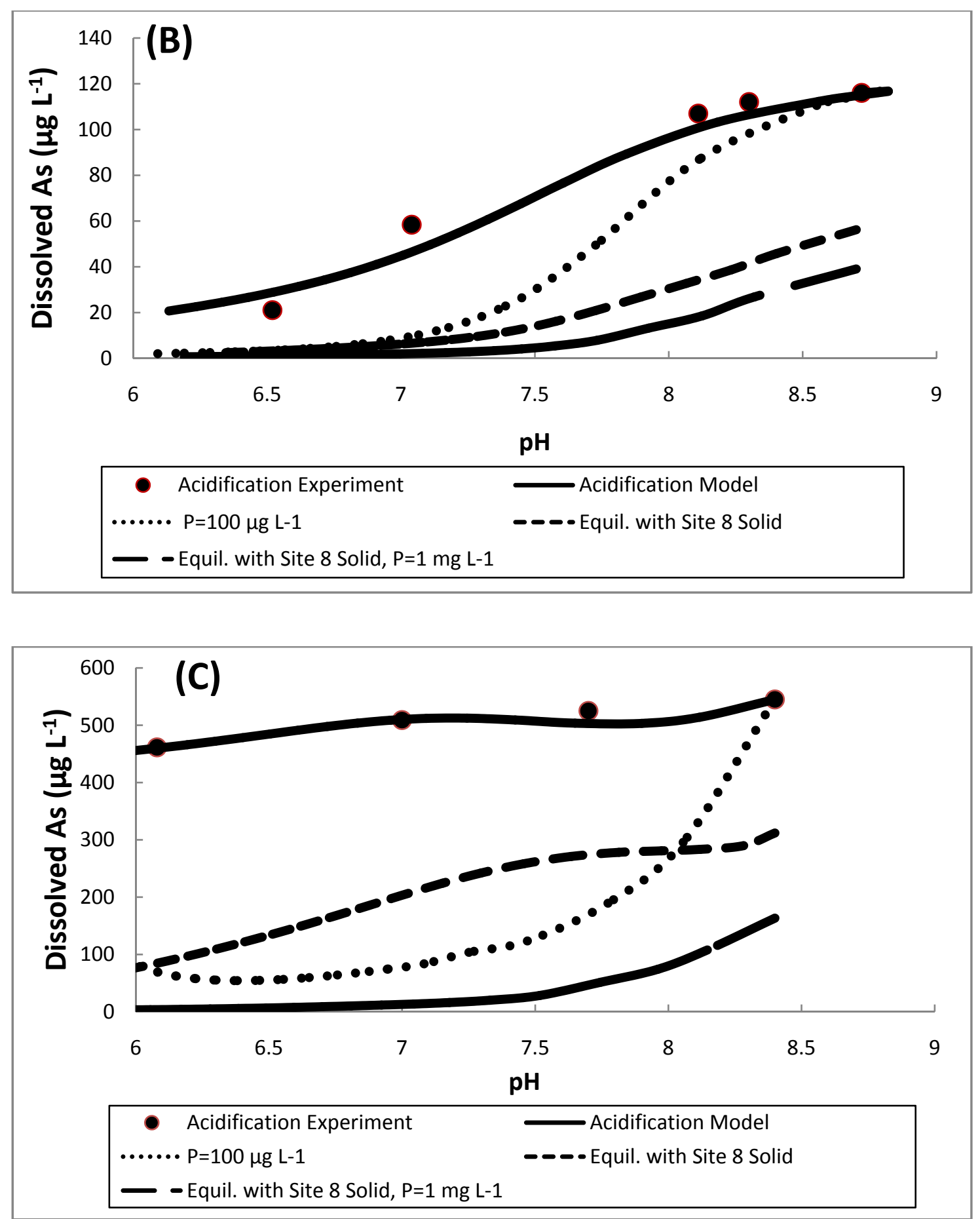

Figure 10. Hybrid-Isotherm Model predictions of $\mathrm{As}(\mathrm{V})$ concentrations for different potential remediation schemes at (A) Site 4, (B) Site 6, and (C) Site 7. 


\section{Conclusions}

Arsenic is mainly present as As(V), arsenate under oxidizing conditions at the study site and was desorbed from the host iron oxide minerals at high $\mathrm{pH}$ values. Laboratory experiments on natural sediment and groundwater samples were conducted to characterize the geochemical conditions at the site, and in order to contribute to the development of models that will allow simulating various remediation strategies. The experimental results expectedly show that the dissolved As concentration in this oxidizing system is overall controlled by $\mathrm{pH}$, number of available sorption sites and presence of competing ions. The hybrid and generalized composite models showed promising results in fitting the experimental data and can be used for guiding future remediation efforts.

In the current study, we used modeling tools PHREEQC and FITEQL, site-specific field and laboratory data, default SCM databases for surface site characteristics (HFO) and surface reaction constants for major ions from literature in order to develop preliminary geochemical models. Models were refined step-wise and the complexation reaction constants were adjusted for achieving the best fit to the experimental data for $\operatorname{As}(\mathrm{V})$ and other major competing ion. The developed Hybrid-Isotherm models were used to simulate different remediation scenarios by incorporating the obtained site-specific reaction constants. This model is based on a hybrid approach to implementing SCM for heterogeneous sorbents and could be used as a best engineering estimate for practical applications.

The different results among the impacted and un-impacted sites indicate that the historical levels of solutes in contact with the sediments play a significant role in analyzing and interpreting the sorptive behavior and retention capacity of such heterogeneous systems.

If the source of $\operatorname{As}(\mathrm{V})$ contamination at this site is the mobilization from natural soils, then the remediation question that needs to be answered is whether and how the conditions can be reversed to immobilize the $\mathrm{As}(\mathrm{V})$. The acidification experiments were moderately successful at lowering $\mathrm{As}(\mathrm{V})$ concentration in Sites 4 and 6. An indication of the modeling results is that even with the extension of the acidification process the $\mathrm{As}(\mathrm{V})$ concentrations in the most affected sites would not meet the EPA standard levels of $10 \mu \mathrm{g} \mathrm{L}^{-1}$. Both experimental and modeling outcomes demonstrate the significant influence of phosphate concentrations on $\mathrm{As}(\mathrm{V})$ attenuation. The 
results indicate that combining methods for removal of dissolved phosphate from sites 6 and 7 could be beneficial to $\mathrm{As}(\mathrm{V})$ immobilization process by reducing the competition factor. The modeling results also show that in addition to lower $\mathrm{pH}$, the number of total HFO sorption sites is the major controlling factor for $\mathrm{As}(\mathrm{V})$ removal. Future column studies are needed to evaluate the predictive capabilities of models for reactive transport of contaminants.

\section{Acknowledgment}

We gratefully acknowledge support from Drumlin Environmental, LLC for conducting this work. This material is based upon research performed in a renovated collaboratory by the

National Science Foundation under Grant No. 0963183, which is an award funded under the American Recovery and Reinvestment Act of 2009 (ARRA). 


\section{References}

Alloway, B. J. (2013). Introduction (pp. 3-9). In Heavy metals in soils. Springer Netherlands.

Anawar, H. M., Akai, J., Mostofa, K. M. G., Safiullah, S., \& Tareq, S. M. (2002). Arsenic poisoning in groundwater: Health risk and geochemical sources in Bangladesh. Environment International, 27(7), 597-604.

Appelo, C. A. J., \& Postma, D. (2005). Geochemistry, groundwater and pollution. CRC press.

Appelo, C. A. J., \& De Vet, W. W. J. M. (2003). Modeling in situ iron removal from groundwater with trace elements such as As. In Arsenic in Ground Water (pp. 381-401). Springer US.

Appelo, C. a J., Van Der Weiden, M. J. J., Tournassat, C., \& Charlet, L. (2002). Surface complexation of ferrous iron and carbonate on ferrihydrite and the mobilization of arsenic. Environmental Science \& Technology, 36(14), 3096-103.

Ayotte, J.D., Nolan, B.T., Nuckols, J.R., Cantor, K.P., Robinson, G.R., Baris, D., Hayes, L., Karagas, M., Bress, W., Silverman, D.T. \& Lubin, J.H. (2006). Modeling the probability of arsenic in groundwater in New England as a tool for exposure assessment. Environmental Science \& Technology, 40(11), 3578-85.

Ayotte, J. D., Montgomery, D. L., Flanagan, S. M., \& Robinson, K. W. (2003). Arsenic in groundwater in eastern New England: occurrence, controls, and human health implications. Environmental science \& technology, 37(10), 2075-2083.

Bhattacharya, P., Claesson, M., Bundschuh, J., Sracek, O., Fagerberg, J., Jacks, G., Martin, R.A., Storniolo, A.D.R. \& Thir, J.M. (2006). Distribution and mobility of arsenic in the Rio Dulce alluvial aquifers in Santiago del Estero Province, Argentina. Science of the Total Environment, 358(1-3), 97-120.

Berg, M., Tran, H. C., Nguyen, T. C., Pham, H. V, Schertenleib, R., \& Giger, W. (2001). Arsenic contamination of groundwater and drinking water in Vietnam: a human health threat. Environmental Science \& Technology, 35(13), 2621-6.

Biswas, A., Gustafsson, J.P., Neidhardt, H., Halder, D., Kundu, A.K., Chatterjee, D., Berner, Z. $\&$ Bhattacharya, P. (2014). Role of competing ions in the mobilization of arsenic in groundwater of Bengal Basin: insight from surface complexation modeling. Water Research, 55, 30-9.

Bolster, C. H., \& Hornberger, G. M. (2008). On the Use of Linearized Langmuir Equations. Soil Science Society of America Journal, 72(6), 1848. 
Bond, D. L., Davis, J. A., \& Zachara, J. M. (2007). Uranium (VI) release from contaminated vadose zone sediments: Estimation of potential contributions from dissolution and desorption. Developments in Earth and Environmental Sciences, 7, 375-416.

Currell, M., Cartwright, I., Raveggi, M., \& Han, D. (2011). Controls on elevated fluoride and arsenic concentrations in groundwater from the Yuncheng Basin, China. Applied Geochemistry, 26(4), 540-552.

Davis, J. A., Meece, D. E., Kohler, M., \& Curtis, G. P. (2004). Approaches to surface complexation modeling of uranium (VI) adsorption on aquifer sediments. Geochimica et Cosmochimica Acta, 68(18), 3621-3641.

Davis, J. A., Coston, J. A., Kent, D. B., \& Fuller, C. C. (1998). Application of the surface complexation concept to complex mineral assemblages. Environmental Science \& Technology, 32(19), 2820-2828.

Dixit, S., \& Hering, J. G. (2003). Comparison of arsenic(V) and arsenic(III) sorption onto iron oxide minerals: implications for arsenic mobility. Environmental Science \& Technology, 37(18), 4182-9.

Dzombak, D. A., \& Morel, F. M. (1990). Surface complexation modeling: hydrous ferric oxide. John Wiley \& Sons.

EPA, U. S. (2002). Arsenic treatment technologies for solid, waste, and water. USEPA Report EPA-542-R-02-004.

Harvey, C. F., Ashfaque, K. N., Yu, W., Badruzzaman, a. B. M., Ali, M. A., Oates, P. M., ... Ahmed, M. F. (2006). Groundwater dynamics and arsenic contamination in Bangladesh. Chemical Geology, 228(1-3), 112-136.

Herbelin, A. L., \& Westall, J. C. (1999). FITEQL: A computer program for determination of chemical equilibrium constants from experimental data. Version, 4, 99-01.

Hiemstra, T., Antelo, J., Rahnemaie, R., \& Riemsdijk, W. H. Van. (2010). Nanoparticles in natural systems I: The effective reactive surface area of the natural oxide fraction in field samples. Geochimica et Cosmochimica Acta, 74(1), 41-58.

Hongshao, Z., \& Stanforth, R. (2001). Competitive adsorption of phosphate and arsenate on goethite. Environmental Science \& Technology, 35(24), 4753-7.

Hyun, S. P., Fox, P. M., Davis, J. A., Campbell, K. M., Hayes, K. F., \& Long, P. E. (2009). Surface complexation modeling of U (VI) adsorption by aquifer sediments from a former mill tailings site at Rifle, Colorado. Environmental science \& technology, 43(24), 93689373. 
Islam, F. S., Gault, A. G., Boothman, C., Polya, D. a, Charnock, J. M., Chatterjee, D., \& Lloyd, J. R. (2004). Role of metal-reducing bacteria in arsenic release from Bengal delta sediments. Nature, 430(6995), 68-71.

Jay, J. a, Blute, N. K., Lin, K., Senn, D., Hemond, H. F., \& Durant, J. L. (2005). Controls on arsenic speciation and solid-phase partitioning in the sediments of a two-basin lake. Environmental Science \& Technology, 39(23), 9174-81. Retrieved from

Jeppu, G. P., \& Clement, T. P. (2012). A modified Langmuir-Freundlich isotherm model for simulating pH-dependent adsorption effects. Journal of Contaminant Hydrology, 129-130, $46-53$.

Jessen, S., Postma, D., Larsen, F., Nhan, P.Q., Trang, P.T.K., Long, T.V., Viet, P.H. \& Jakobsen, R. (2012). Surface complexation modeling of groundwater arsenic mobility: Results of a forced gradient experiment in a Red River flood plain aquifer, Vietnam. Geochimica et Cosmochimica Acta, 98, 186-201.

Jung, H. B., Bostick, B. C., \& Zheng, Y. (2012). Field, experimental, and modeling study of arsenic partitioning across a redox transition in a bangladesh aquifer. Environmental Science and Technology, 46(3), 1388-1395.

Kanel, S. R., Manning, B., Charlet, L., \& Choi, H. (2005). Removal of arsenic(III) from groundwater by nanoscale zero-valent iron. Environmental Science \& Technology, 39(5), 1291-8.

Kanematsu, M., Young, T. M., Fukushi, K., Green, P. G., \& Darby, J. L. (2012). Individual and combined effects of water quality and empty bed contact time on As(V) removal by a fixedbed iron oxide adsorber: implication for silicate precoating. Water Research, 46(16), 506170 .

Keon, N. E., Swartz, C. H., Brabander, D. J., Harvey, C., \& Hemond, H. F. (2001). Validation of an arsenic sequential extraction method for evaluating mobility in sediments.

Environmental Science \& Technology, 35(13), 2778-84.

Komárek, M., Vaněk, A., \& Ettler, V. (2013). Chemical stabilization of metals and arsenic in contaminated soils using oxides--a review. Environmental Pollution (Barking, Essex : 1987), 172, 9-22.

Larsen, F., Pham, N.Q., Dang, N.D., Postma, D., Jessen, S., Pham, V.H., Nguyen, T.B., Trieu, H.D., Tran, L.T., Nguyen, H. \& Chambon, J. (2008). Controlling geological and hydrogeological processes in an arsenic contaminated aquifer on the Red River flood plain, Vietnam. Applied Geochemistry, 23(11), 3099-3115.

Lawson, M., Polya, D. a, Boyce, A. J., Bryant, C., Mondal, D., Shantz, A., \& Ballentine, C. J. (2013). Pond-derived organic carbon driving changes in arsenic hazard found in Asian groundwaters. Environmental Science \& Technology, 47(13), 7085-94. 
Mai, N. T. H., Postma, D., Trang, P. T. K., Jessen, S., Viet, P. H., \& Larsen, F. (2014). Adsorption and desorption of arsenic to aquifer sediment on the Red River floodplain at Nam Du, Vietnam. Geochimica et Cosmochimica Acta, 142, 587-600.

Manning, B. A., \& Goldberg, S. (1996). Modeling Competitive Adsorption of Arsenate with Phosphate and Molybdate on Oxide Minerals. Soil Science Society of America Journal, $60(1), 121$.

Martínez-Villegas, N., Briones-Gallardo, R., Ramos-Leal, J. a, Avalos-Borja, M., CastañónSandoval, A. D., Razo-Flores, E., \& Villalobos, M. (2013). Arsenic mobility controlled by solid calcium arsenates: a case study in Mexico showcasing a potentially widespread environmental problem. Environmental Pollution (Barking, Essex : 1987), 176, 114-22.

Masue, Y., Loeppert, R. H., \& Kramer, T. a. (2007). Arsenate and arsenite adsorption and desorption behavior on coprecipitated aluminum:iron hydroxides. Environmental Science \& Technology, 41(3), 837-42.

McArthur, J.M., Banerjee, D.M., Hudson-Edwards, K.A., Mishra, R., Purohit, R., Ravenscroft, P., Cronin, A., Howarth, R.J., Chatterjee, A., Talukder, T. \& Lowry, D . (2004). Natural organic matter in sedimentary basins and its relation to arsenic in anoxic ground water: the example of West Bengal and its worldwide implications. Applied Geochemistry, 19(8), $1255-1293$.

Moldovan, B. I., \& Hendry, M. J. (2005). Characterizing and quantilying controls on arsenic solubility over a $\mathrm{pH}$ range of 1-11 in a uranium mill-scale experiment. Environmental Science \& Technology, 39(13), 4913-20.

Neumann, R. B., Ashfaque, K. N., Badruzzaman, a. B. M., Ashraf Ali, M., Shoemaker, J. K., \& Harvey, C. F. (2009). Anthropogenic influences on groundwater arsenic concentrations in Bangladesh. Nature Geoscience, 3(1), 46-52.

Neupane, G., Donahoe, R. J., \& Arai, Y. (2014). Kinetics of competitive adsorption/desorption of arsenate and phosphate at the ferrihydrite-water interface. Chemical Geology, 368, 3138.

Neidhardt, H., Berner, Z.A., Freikowski, D., Biswas, A., Majumder, S., Winter, J., Gallert, C., Chatterjee, D. \& Norra, S. (2014). Organic carbon induced mobilization of iron and manganese in a West Bengal aquifer and the muted response of groundwater arsenic concentrations. Chemical Geology, 367, 51-62.

Nicolli, H. B., Bundschuh, J., Blanco, M. D. C., Tujchneider, O. C., Panarello, H. O., Dapena, C., \& Rusansky, J. E. (2012). Arsenic and associated trace-elements in groundwater from the Chaco-Pampean plain, Argentina: Results from 100years of research. Science of the Total Environment, 429, 36-56. 
O’Day, P. a, Vlassopoulos, D., Root, R., \& Rivera, N. (2004). The influence of sulfur and iron on dissolved arsenic concentrations in the shallow subsurface under changing redox conditions. Proceedings of the National Academy of Sciences of the United States of America, 101(38), 13703-8.

Omoregie, E.O., Couture, R.M., Van Cappellen, P., Corkhill, C.L., Charnock, J.M., Polya, D.A., Vaughan, D., Vanbroekhoven, K. \& Lloyd, J.R. (2013). Arsenic bioremediation by biogenic iron oxides and sulfides. Applied and Environmental Microbiology, 79(14), 4325-35.

Oremland, R. S., \& Stolz, J. F. (2005). Arsenic, microbes and contaminated aquifers. Trends in microbiology, 13(2), 45-49.

Parkhurst, D. L., \& Appelo, C. A. J. (2013). Description of input and examples for PHREEQC version 3: a computer program for speciation, batch-reaction, one-dimensional transport, and inverse geochemical calculations (No. 6-A43). US Geological Survey.

Polya, D.A., Gault, A.G., Diebe, N., Feldman, P., Rosenboom, J.W., Gilligan, E., Fredericks, D., Milton, A.H., Sampson, M., Rowland, H.A.L. \& Lythgoe, P.R. (2005). Arsenic hazard in shallow Cambodian groundwaters. Mineralogical Magazine, 69(5), 807-823.

Postma, D., Larsen, F., Minh Hue, N. T., Duc, M. T., Viet, P. H., Nhan, P. Q., \& Jessen, S. (2007). Arsenic in groundwater of the Red River floodplain, Vietnam: Controlling geochemical processes and reactive transport modeling. Geochimica et Cosmochimica Acta, 71(21), 5054-5071.

Quicksall, A. N., Bostick, B. C., \& Sampson, M. L. (2008). Linking organic matter deposition and iron mineral transformations to groundwater arsenic levels in the Mekong delta, Cambodia. Applied Geochemistry, 23(11), 3088-3098.

Radloff, K.A., Zheng, Y., Michael, H.A., Stute, M., Bostick, B.C., Mihajlov, I., Bounds, M., Huq, M.R., Choudhury, I., Rahman, M.W. and Schlosser, P.. (2011). Arsenic migration to deep groundwater in Bangladesh influenced by adsorption and water demand. Nature Geoscience, 4(11), 793-798.

Radu, T., Kumar, A., Clement, T. P., Jeppu, G., \& Barnett, M. O. (2008). Development of a scalable model for predicting arsenic transport coupled with oxidation and adsorption reactions. Journal of contaminant hydrology, 95(1), 30-41.

Raven, K. P., Jain, A., \& Loeppert, R. H. (1998). Arsenite and arsenate adsorption on ferrihydrite: Kinetics, equilibrium, and adsorption envelopes. Environmental Science and Technology, 32(3), 344-349.

Ravenscroft, P., Brammer, H., \& Richards, K. (2009). Arsenic pollution: a global synthesis (Vol. 28). John Wiley \& Sons. 
Robertson, F. N. (1989). Arsenic in ground-water under oxidizing conditions, south-west United States. Environmental Geochemistry and Health, 11(3-4), 171-185.

Robinson, C., Von Broemssen, M., Bhattacharya, P., Häller, S., Bivén, A., Hossain, M., Jacks, G., Ahmed, K.M., Hasan, M.A. \& Thunvik, R. (2011). Dynamics of arsenic adsorption in the targeted arsenic-safe aquifers in Matlab, south-eastern Bangladesh: Insight from experimental studies. Applied Geochemistry, 26(4), 624-635.

Rowland, H.A.L., Pederick, R.L., Polya, D.A., Pancost, R.D., Van Dongen, B.E., Gault, A.G., Vaughan, D.J., Bryant, C., Anderson, B. \& Lloyd, J.R. (2007). The control of organic matter on microbially mediated iron reduction and arsenic release in shallow alluvial aquifers, Cambodia. Geobiology, 5(3), 281-292.

Scanlon, B. R., Nicot, J. P., Reedy, R. C., Kurtzman, D., Mukherjee, a., \& Nordstrom, D. K. (2009). Elevated naturally occurring arsenic in a semiarid oxidizing system, Southern High Plains aquifer, Texas, USA. Applied Geochemistry, 24(11), 2061-2071.

Sharif, M. S. U., Davis, R. K., Steele, K. F., Kim, B., Hays, P. D., Kresse, T. M., \& Fazio, J. a. (2011). Surface complexation modeling for predicting solid phase arsenic concentrations in the sediments of the Mississippi River Valley alluvial aquifer, Arkansas, USA. Applied Geochemistry, 26(4), 496-504.

Sherman, D. M., \& Randall, S. R. (2003). Surface complexation of arsenic (V) to iron (III)(hydr) oxides: structural mechanism from ab initio molecular geometries and EXAFS spectroscopy. Geochimica et Cosmochimica Acta, 67(22), 4223-4230.

Smedley, P. L., Kinniburgh, D. G., Macdonald, D. M. J., Nicolli, H. B., Barros, a. J., Tullio, J. O., Alonso, M. S. (2005). Arsenic associations in sediments from the loess aquifer of La Pampa, Argentina. Applied Geochemistry, 20, 989-1016.

Smedley, P. L., \& Kinniburgh, D. G. (2002). A review of the source, behaviour and distribution of arsenic in natural waters. Applied Geochemistry, 17(5), 517-568.

Smith, a H., Hopenhayn-Rich, C., Bates, M. N., Goeden, H. M., Hertz-Picciotto, I., Duggan, H. M., Smith, M. T. (1992). Cancer risks from arsenic in drinking water. Environmental Health Perspectives, 97(6), 259-67.

Sracek, O., Bhattacharya, P., Jacks, G., Gustafsson, J.-P., \& Brömssen, M. Von. (2004). Behavior of arsenic and geochemical modeling of arsenic enrichment in aqueous environments. Applied Geochemistry, 19(2), 169-180.

Stollenwerk, K.G., Breit, G.N., Welch, A.H., Yount, J.C., Whitney, J.W., Foster, A.L., Uddin, M.N., Majumder, R.K. \& Ahmed, N. (2007). Arsenic attenuation by oxidized aquifer sediments in Bangladesh. The Science of the Total Environment, 379(2-3), 133-50. 
Stollenwerk, K. G. (2003). Geochemical processes controlling transport of arsenic in groundwater: a review of adsorption. In Arsenic in ground water (pp. 67-100). Springer US.

Swedlund, P. J., \& Webster, J. G. (1999). Adsorption and polymerisation of silicic acid on ferrihydrite, and its effect on arsenic adsorption. Water Research, 33(16), 3413-3422.

Van Geen, a., Zheng, Y., Cheng, Z., Aziz, Z., Horneman, a., Dhar, R. K., Ahmed, K. M. (2006). A transect of groundwater and sediment properties in Araihazar, Bangladesh: Further evidence of decoupling between As and Fe mobilization. Chemical Geology, 228(1-3), 8596.

Wang, S., \& Mulligan, C. N. (2006). Natural attenuation processes for remediation of arsenic contaminated soils and groundwater. Journal of Hazardous Materials, 138(3), 459-70.

Welch, A. H., Westjohn, D. B., Helsel, D. R., \& Wanty, R. B. (2000). Arsenic in Ground Water of the United States-Occurrence and Geochemistry. Ground Water, 38(4), 589-604.

WHO-Word Health Organizaton (2011). Guideline for drinking-water quality, Fourth edition. On line: http://www.who.int/publications/2011/9789241548151_eng.pdf.

Wilkie, J. A., \& Hering, J. G. (1996). Adsorption of arsenic onto hydrous ferric oxide: effects of adsorbate/adsorbent ratios and co-occurring solutes. Colloids and Surfaces A:

Physicochemical and Engineering Aspects, 107, 97-110.

Zheng, Y., Stute, M., Van Geen, A., Gavrieli, I., Dhar, R., Simpson, H.J., Schlosser, P. \& Ahmed, K.M. (2004). Redox control of arsenic mobilization in Bangladesh groundwater. Applied Geochemistry, 19(2), 201-214. 